\title{
Foodomics: \\ MS-based Strategies in Modern Food Science and Nutrition
}

Miguel Herrero, Carolina Simó, Virginia García-Cañas, Elena Ibáñez, Alejandro Cifuentes*

Institute of Food Science Research (CIAL), CSIC, Nicolas Cabrera 9, Campus de Cantoblanco, 28049 Madrid, Spain

Keywords: foods, functional foods, new foods, metabolomics, proteomics, nutrigenomics, nutrigenetics

Title (short version): MS methodologies in Foodomics

*Corresponding author: Prof. Alejandro Cifuentes, Tel: 34-91-5618806 Fax\#: 34-915644853, e-mail: a.cifuentes@ csic.es 


\section{TABLE OF CONTENTS}

\section{INTRODUCTION TO FOODOMICS.}

A. Definition of Foodomics, fundamentals, and tools.

B. New challenges in modern food safety, quality, and traceability studies.

C. Functional foods, nutrition, and health research: A Foodomics approach.

\section{MASS SPECTROMETRY IN FOODOMICS.}

A. Food safety, quality, and traceability, with MS-based "omics" approaches.

1. Detection of exogenous contaminants in food.

2. Detection of food allergens.

3. Detection of pathogens and toxins.

4. Food quality and geographical origin assessment.

5. Food traceability.

B. MS-based methodologies to develop and characterize transgenic foods.

1. Proteomics

2. Metabolomics

C. Foodomics in nutrition and health research. MS-based "omics" approaches in Nutrigenomics, Nutriproteomics, and Nutrimetabolomics.

III. FOODOMICS, MS-BASED METHODOLOGIES, AND SYSTEMS BIOLOGY.

IV. FUTURE TRENDS IN FOODOMICS.

ACKNOWLEDGEMENTS.

REFERENCES. 


\section{LIST OF ABBREVIATIONS.}

2-DE, two dimensional gel electrophoresis

APCI, atmospheric pressure chemical ionization

BGE, background electrolyte

$\mathrm{CE}$, capillary electrophoresis

CID, collision-induced dissociation

DART, direct analysis in real time

DIGE, differential in-gel electrophoresis

ESI, electrospray interface

FIA, flow-injection analysis

FID, flame ionization detection

FT-ICR, Fourier-transform ion cyclotron resonance

GC, gas chromatography

GCxGC, two-dimensional comprehensive gas chromatography

GMO, genetically modified organism

HCA, hierarchical clustering analysis

HILIC, hydrophilic interaction liquid chromatography

ICA, independent component analysis

ICAT, isotope coded affinity tags

ICP, induced coupled plasma

IRMS, isotope ratio MS

IT, ion trap

LC, liquid chromatography

LCxLC, two-dimensional comprehensive liquid chromatography

LOD, limit of detection

LOQ, limit of quantification

LVI, large-volume injections

MALDI, matrix-assisted laser desorption/ionization

MRL, maximum residue level

MRM, multiple reaction monitoring

MW, molecular weight

NMR, nuclear magnetic resonance

OPLS-DA, orthogonal projection-discriminant analysis

PAGE, polyacrylamide gel electrophoresis

$\mathrm{PAH}$, polycyclic aromatic hydrocarbons

PCA, principal component analysis

PCB, polychlorinated biphenyls

PLE, pressurized liquid extraction

PLS-DA, partial least square discriminant analysis

Q, quadrupole

QqQ, triple quadrupole

QuEChERS, quick, easy, cheap, effective, rugged, and safe

SELDI, surface-enhanced laser desorption/ionization

SFE, supercritical fluid extraction

SPE, solid-phase extraction

SNP, single nucleotide polymorphism

TOF, time-of-flight

UPLC, ultra-performance liquid chromatography 


\begin{abstract}
Modern research in food science and nutrition is moving from classical methodologies to advanced analytical strategies in which MS-based techniques play a crucial role. In this context, Foodomics has been recently defined as a new discipline that studies food and nutrition domains through the application of advanced omics technologies in which MS techniques are considered indispensable. Applications of Foodomics include the genomic, transcriptomic, proteomic, and/or metabolomic study of foods for compound profiling, authenticity, and/or biomarker-detection related to food quality or safety; the development of new transgenic foods, food contaminants, and whole toxicity studies; new investigations on food bioactivity, food effects on human health, etc. This review work does not intend to provide an exhaustive revision of the many works published so far on food analysis using MS techniques. The aim of the present work is to provide an overview of the different MS-based strategies that have been (or can be) applied in the new field of Foodomics, discussing their advantages and drawbacks. Besides, some ideas about the foreseen development and applications of MS-techniques in this new discipline are also provided.
\end{abstract}




\section{INTRODUCTION TO FOODOMICS.}

Interaction of modern food science and nutrition with disciplines such as pharmacology, medicine, or biotechnology provides impressive new challenges and opportunities. As a result, researchers in food science and nutrition are moving from classical methodologies to more advanced strategies, and usually borrow methods well established in medical, pharmacological, and/or biotechnology research. As a result, advanced analytical methodologies, "omics" approaches and bioinformatics -frequently together with in-vitro, in-vivo, and/or clinical assays- are applied to investigate topics in food science and nutrition that were considered unapproachable few years ago.

In modern food science and nutrition, terms such as nutrigenomics, nutrigenetics, nutritional genomics, transgenics, functional foods, nutraceuticals, genetically modified (GM) foods, nutritranscriptomics, nutriproteomics, nutrimetabolomics, systems biology, etc., are expanding (Powell, 2007; Rezzi et al., 2007; Rist, Wenzel \& Daniel, 2006; Subbiah, 2006; Trujillo, Davis \& Milner, 2006). This novelty has also brought about some problems related to the poor definition of part of this terminology or their low acceptance (Ronteltap, van Trijp \& Renes, 2007), probably due to the difficulty to work in a developing field in which several emerging strategies are frequently put together.

\section{A. Definition of Foodomics, fundamentals, and tools.}

In this context, Foodomics has been defined as a new discipline that studies the food and nutrition domains through the application of advanced omics technologies in order to improve consumer's well-being, health, and confidence (Cifuentes, 2009; Herrero et 
al., 2010). Thus, Foodomics is intended to be not only an useful concept to cover in a simple and straightforward way all of the abovementioned new terminology, but more importantly, it is intended to be a global discipline that includes all of the emerging working areas in which food (including nutrition), advanced analytical techniques (mainly omics tools), and bioinformatics are combined. A representation of the areas covered by Foodomics and its main goals can be seen in Figure 1. For instance, Foodomics would cover the development of new transgenic foods with molecular tools, the genomic/transcriptomic/proteomic and/or metabolomic study of foods for compound profiling/authenticity and/or biomarkers analysis related to food quality, new investigations on food bioactivity and its effect on human health following nutrigenomics and/or nutrigenetics approaches, development of global omics strategies to explore food safety issues, etc. The interest in Foodomics also coincides with a clear shift in medicine and biosciences toward prevention of future diseases through adequate food intakes, and the development of the so-called functional foods that will be discussed below.

Foodomics involves the use of multiple tools to deal with the different applications included in this field. Thus, the use of omics tools such as genomics, transcriptomics, proteomics, and metabolomics is a must in this new discipline. MSbased techniques are crucial for proteomics and metabolomics studies.

Proteomes differ among individuals, cell types, and within the same cell, depending on cell activity and state. An important challenge in proteomic studies is the wide difference in concentration from the most- to the least-abundant proteins (i.e., a dynamic range of $10^{10}$ has been estimated for protein concentration in serum) that 
makes proteome analysis a challenging task. The increasing popularity of proteomics has created a need for quantitative analysis methods. As a result, many different techniques are now available for performing gel-based or gel-free quantitative proteomics. These techniques provide an insight into global protein expression from identification to quantification (Szopinska et al. 2010).

Main sample preparation methods to reduce proteome complexity include, fractionation, depletion, as well as enrichment of low-abundant proteins. Figure 2 shows a scheme of the different strategies that can be followed in order to carry out a proteomic study including "bottom-up", "shotgun" and "top-down" approaches. MS is used in these strategies as the last analytical step for peptide detection and protein identification. At present, MS represents the most-powerful tool in proteomics because it requires no prior knowledge of the proteins to be identified (Motoyama \& Yates, 2008; Yates, Ruse \& Nakorchevsky, 2009; Han, Aslnian \& Yates, 2008). MS also enables the analysis of proteins and peptides in large-scale and high-throughput modes. Improved mass spectrometers with better sensitivity and superior mass accuracy and resolution aim to identify and quantify complex protein (peptides) mixtures in a single experiment. Main mass analyzers used in proteomics are time-of-flight (TOF), quadrupole (Q), Fourier transform ion cyclotron resonance (FT-ICR), and ion trap (IT), which are usually combined in one mass spectrometer (triple quadrupole (QqQ), Q-IT, Q-TOF, TOF-TOF, IT-FTMS, etc.). Typically, mass spectrometry can cover a dynamic range up to four orders of magnitude.

On the other hand, the metabolome can be defined as the full set of endogenous or exogenous low molecular weight metabolic entities of approximately <1000 Da 
(metabolites), and the small pathway motifs that are present in a biological system (cell, tissue, organ, organism or species) (Trujillo, Davis \& Milner, 2006). Metabolites are, in general, the final downstream products of the genome, and reflect most closely the operation of the biological system, its phenotype. The analysis of metabolic patterns and changes in the metabolism in the nutrition field can be, therefore, very interesting to locate; e.g., variations in different metabolic pathways due to the consumption of different compounds in the diet. One of the main challenges in metabolomics is to face the complexity of any metabolome, usually composed by a huge number of compounds of very diverse chemical and physical properties (sugars, amines, amino acids, peptides, organic acids, nucleic acid, or steroids). Sample preparation is especially important in metabolomics, because the procedure used for metabolite extraction has to be robust and highly reproducible. Sample preparation will depend on the sample type and the targeted metabolites of interest (fingerprinting or profiling approach). Moreover, no single analytical methodology or platform is applicable to detect, quantify, and identify all metabolites in a certain sample. Two analytical platforms are currently used for metabolomic analyses: MS and NMR-based systems. These techniques either stand alone or combined with separation techniques (typically, LC-NMR, GC-MS, LC-MS and CE-MS), can produce complementary analytical information to attain more extensive metabolome coverage (Shulaev, 2006). MS and NMR-based technologies are both complementary and, therefore, often used in parallel in metabolomic research. Compared to NMR, MS is a more-sensitive technique; also, MS coupled to GC, LC, or CE allows higher resolution and sensitivity for low-abundance metabolites (Xiayan \& Legido-Quigley, 2008; Garcia et al., 2008; Dettmer, Aronov \& Hammock, 2007; Issaq et al., 2009). The use of high and ultra-high resolution analyzers (namely, TOF, FTMS, Orbitrap $^{\circledR}$ ) is essential to obtain accurate mass measurements for the determination of 
elemental compositions of metabolites, and to carry out their tentative identification with databases (Xu et al., 2010; Brown, Kruppa \& Dasseux, 2005). On the other hand, MS/MS or $\mathrm{MS}^{\mathrm{n}}$ experiments, especially when product ions are analyzed at high resolution (with Q-TOF, TOF-TOF or LTQ-Orbitrap ${ }^{\circledR}$ ) provide additional structural information for the identification of metabolites. Although there are three basic approaches used in any metabolomic study (target analysis, metabolic profiling, and metabolic fingerprinting), we will focus in this review on metabolic profiling and metabolic fingerprinting. Metabolic profiling focuses on the analysis of a group of metabolites that are either related to a specific metabolic pathway or a class of compounds. On the other hand, the goal in metabolic fingerprinting is the comparison of patterns of metabolites that change in response to a disease, a treatment, environmental or genetic alterations, etc.

Due to the huge amount of data usually obtained from these omics studies, it has been necessary to develop strategies to convert the complex raw data obtained into useful information. Thus, bioinformatics has become a crucial tool in Foodomics. Over the last years, the use of biological knowledge accumulated in public databases allows one to systematically analyze with bioinformatics large data lists in an attempt to assemble a summary of the most significant biological aspects (Waagmeester, Kelder \& Evelo 2008). Also, statistical tools are usually applied; e.g., for exploratory data analysis to determine correlations among samples (which can be caused by either a biological difference or a methodological bias), to discriminate the complete data list and reduce it with the most relevant ones, for biomarkers discovery, etc.

\section{B. New challenges in modern food safety, quality, and traceability studies.}


Foodomics can help to solve some of the new challenges that modern food safety, quality, and traceability have to face. These challenges encompass the multiple analysis of contaminants, the establishment of more-powerful analytical methodologies to guarantee food origin and quality, the discovery of biomarkers to detect unsafe products or the capability to detect food safety problems before they grow and affect more consumers, etc. A good example of the application of advanced approaches in food science is the development of transgenic (also called genetically modified, GM) foods in which molecular biology, chemistry, agriculture, and food science are combined in order to adequately develop these new foods. Moreover, the monitoring of the composition, traceability, and quality of these GM foods has been recommended with advanced analytical techniques (EFSA, 2006), including -omics techniques to provide a broad profile of these GM foods (Garcia-Villaba et al., 2010; Levandi et al., 2008; Simó et al., 2010). The development of new analytical strategies based on Foodomics will provide extraordinary opportunities to increase our understanding about GMOs, including the investigation on unintended effects in GM crops, or the development of the so-called second generation GM foods (García-Villalba et al., 2008; Levandi et al., 2008; Simó et al., 2010). Besides, Foodomics has to deal with the particular difficulties commonly found in food analysis, such as the huge dynamic concentration range of food components as well as the heterogeneity of food matrices and the analytical interferences typically found in these complex matrices.

Moreover, the combined use in Foodomics of advanced analytical methodologies with other more classical approaches, such as toxicity studies, in-vitro or in-vivo assays, and/or clinical trials, can provide an important added value to the results. 
Some examples of these applications that will be discussed below in section 2 of this review work, will pay special attention to the MS-based strategies.

\section{Functional foods, nutrition, and health research: A Foodomics approach.}

One of the main goals in modern food science and nutrition is to improve our limited understanding of the roles of nutritional compounds at the molecular level (i.e., their interaction with genes, and their subsequent effect on proteins and metabolites). This knowledge should allow the rational design of strategies to manipulate cell functions through diet; that goal is expected to have an extraordinary impact on our health. However, unlike pharmaceuticals, the simultaneous presence of a variety of nutrients, with diverse chemical structures and concentrations, and with numerous targets with different affinities and specificities increases enormously the complexity of the problem. The development of genomics, transcriptomics, proteomics, and metabolomics provides extraordinary opportunities to increase our understanding in regards to this huge variability addressed by Foodomics. A detailed description on genomics and transcriptomics is out of the scope of this paper (readers interested on these topics can find useful information elsewhere (Dettmer, Aronov \& Hammock, 2007; García-Cañas et al., 2010; Griffiths \& Wang, 2009; Raqib \& Cravioto, 2009), which will focus on MS-based strategies in the new field of Foodomics with special emphasis in proteomics and metabolomics applications.

\section{MASS SPECTROMETRY IN FOODOMICS.}

A. Food safety, quality, and traceability with MS-based “omics” approaches. 


\section{Detection of exogenous contaminants in food.}

Food safety is today a challenging field in which modern analytical chemistry must provide accurate, precise, and robust methods to determine any harmful compounds or organisms that might be present in food at very low concentrations. The evolution of MS and the application of Foodomics technologies have a very significant impact on this field, and improve even further the limits demanded by food safety legislation. A clear example of this trend is the continuous development of multi-residue methods for the sensitive determination of contaminants in food, mainly pesticides and antimicrobials. The employment of these classes of compounds is common practice in agriculture and farming to prevent possible issues that might threaten the correct growth of crops and animals. However, in order to limit and control the use of these compounds, and to consequently protect the health of the consumers, the legislation of different countries imposes strict maximum residue levels (MRLs) - defined as the maximum amount of a particular compound that might reach the final food product (Bohm, Stachel \& Gowik, 2009). These limits are established so that the employment of these compounds does not pose a risk for human health, whereas the use of some of them is strictly forbidden. The use of MS coupled to other analytical techniques, mainly separation methods, allows the simultaneous and sensitive determination of these compounds in food matrices. In Table 1, some representative researches recently published on the simultaneous analysis of more than 30 pesticides and/or antimicrobials are summarized. Table 1 shows that modern mass spectrometers allow the simultaneous and sensitive quantification of diverse groups of compounds in different food matrices. Several advanced separation techniques are typically coupled to MS instruments to develop this kind of applications, as shown in Table 1. Independently from the 
analytical tool selected, MS/MS analyses are performed in which two product-ions are usually selected for each precursor-ion for these determinations (in Comission decision 2002/657/EC). Multiple reaction monitoring (MRM) is the most frequently employed mode to selectively measure the intensity of the quantifier ion. The other product-ion, normally called a qualifier ion, confirms the positive identification of the contaminant. Besides the ionization source settings, the collision-induced dissociation (CID) parameters for the in-source CID fragmentation are of great importance, and should be carefully optimized, because they have a strong influence on the sensitivity. Besides, in order to acquire precise and reproducible results, the calibration performed must be closely evaluated. Internal and external standard calibrations have both been applied. Whereas the contaminants must be usually extracted from the "real" sample in a step previous to their analysis, matrix-matched calibrations are frequently used (Economou et al., 2009). This kind of procedure facilitates the selection of the calibration method by observing statistically whether the sample matrix positively or negatively influences the results. Some matrices could have a negative effect in the ionization of the analytes (an inhibition effect), whereas others might promote the ionization of the studied contaminants (Carretero et al., 2008).

Among the coupled analytical techniques employed for these applications, the combination of liquid chromatography (LC) with electrospray interface (ESI) and triple quadrupole analyzers is the most frequently used. This technique has been successfully employed to determine pesticides in fruits (Wong et al., 2010), vegetables (Chung \& Chan, 2010), wines (Economou et al., 2009), milk (Dagnac et al., 2009), or meat (Carretero, Blasco \& Pico, 2008), for example. Solid-phase extraction or QuEChERS (abbreviation of Quick, Easy, Cheap, Effective, Rugged, and Safe) are the most- 
employed sample pretreatment methods. With LC-MS/MS, values of LOQs as low as few $\mu \mathrm{g} \mathrm{Kg}^{-1}$ are generally reached; also, the analyses are relatively fast. For instance, 58 antibiotics were analyzed in milk in less than 15 min (Gaugain-Juhel et al., 2009). However, the selective detection of the triple quadrupole analyzers allows the accurate analysis of incompletely separated compounds. In fact, in almost the same analysis time (i.e., $14 \mathrm{~min}$ ), 191 pesticides residues were determined from different fruits (Wong et al., 2010a). In order to further speed-up these separations, nowadays, short columns with smaller particle diameters are also employed, to produce separations at ultra-high pressures in UPLC. With this equipment, more than 100 pesticides were analyzed in strawberry samples in less than 5 min (Taylor et al., 2008). Gas chromatography (GC) is other technique routinely coupled to triple quadrupole analyzers to determine food contaminants. GC presents a series of advantages over LC, such as lower use of organic solvents or higher efficiency; however, the separations are usually slower and the sensitivity might be compromised. Nevertheless, GC-MS/MS methods of comparable high throughput have been also developed; for instance, for the separation and quantification of more than 160 pesticides residues in vegetables (Wong et al., 2010b), to attain limits of detection similar to those obtained with LC-MS/MS. Besides, other approaches such as large-volume injections (LVI) can be employed to further improve the GC-MS sensitivity (Xu et al., 2009). Although some GC-MS research has employed the SIM mode to detect and quantify the contaminants (mainly due to the higher accessibility to a single quadrupole instrument), it has been demonstrated how the use of GC-MS/MS significantly increases the specificity, sensitivity, and reliability of the method (Wong et al., 2010b). Also recently, comprehensive two-dimensional GC (GCxGC) has been used to quantitatively determine more than 100 pesticides by coupling GCxGC to TOF-MS (Van der Lee et al., 2008). This technique is gaining 
attention due to its capability to characterize unknown samples. However, quantitative analyses have not been reported extensively, mainly due to problems related to data handling. Nevertheless, this technique can quantify multiple pesticides with an LOQ at $\mu \mathrm{g} \mathrm{kg}^{-1}$ levels (Van der Lee et al., 2008). Although conventional GC-MS is a more affordable technique, the coupling of two different separation mechanisms in GCxGCMS through a modulator allows increasing the separation power, while introducing different separation mechanisms. Besides, a characteristic of GCxGC-MS compared to GC-MS is its increased signal-to-noise ratio thanks to the refocus of a chromatographic band produced in the modulator and its subsequent release to the second dimension separation. In Figure 3, the three-dimensional and contour plots that correspond to a separation of a high number of pesticides with GCxGC-TOF-MS is shown. The increased separation power of this technique as well as an appropriate modulation between the two dimensions might improve the detection capabilities of the mass spectrometers and enhance the sensitivity. Similar approaches can also be employed for the determination of other contaminants in food, e.g., from environment or compounds that might migrate from packing materials, as polychlorinated biphenyls (PCBs), polycyclic aromatic hydrocarbons (PAHs), heterocyclic amines or phthalates (Malik, Blasco \& Pico, 2010).

\section{Detection of food allergens.}

The detection of food allergens is a hot topic in the food safety field. Food allergens are naturally present in some foods, and might induce adverse reactions in susceptible individuals. The interest on food allergies keeps therefore increasing, while a complete cure for the different food allergies is not yet available. Thus, allergic patients are forced to avoid the consumption of the allergen, even in very small quantities. This fact has led 
to tighter legislation by food control agencies (FDA, EFSA, etc), in order to make clear in the food labels the presence and/or amount of the most-common food allergens. A relatively high number of proteins have been identified as food allergens in different food products, such as dairy products, eggs, soybeans, peanuts, cereals or fish, for instance. Consequently, proteomics has become a very useful tool for the identification of allergens in food products. In this regard, MS is widely used for the sensitive detection and identification of allergen food proteins. Up to now, the bottom-up proteomics strategy is the most widely used method for the detection of food allergens. As mentioned above, this strategy includes protein digestion in order to produce a set of peptides derived from the different proteins contained in the sample and their identification as a part of a particular protein. This approach has been used, for instance, to combine capillary LC with Q-TOF MS in order to select a series of peptides as markers for the presence of the three major peanut allergens (Ara-h1, Ara-h2, and Arah3) in food products independently of the use as raw or roasted peanuts (Chaissaigne, Norgaard \& Van Hengel, 2007). This fact was shown to be very important because roasting significantly affected the detectability of a large number of ions derived from these allergens. Therefore, the development of this strategy allows the detection and identification of traces of peanut allergens in products that might non-intentionally contain peanuts. In fact, similar approaches have demonstrated their capabilities to detect concentrations of peanut allergen proteins as low as $1 \mu \mathrm{g} \mathrm{g}^{-1}$ in complex food products, such as rice crispy/chocolate-based snacks (Careri et al., 2007). On the other hand, the use of MS to characterize intact allergen proteins previously detected with immunoblotting with sera from allergic patients has been also extensively carried out. This approach was recently proved to be useful to determine that the $\alpha$ - and $\beta$-subunits of $\beta$-conglycinin were also potential soybean allergens (Krishnan et al., 2009). These 
two proteins subunits were identified with MALDI-TOF MS after immunoblotting soybean proteins with sera from soybean-allergic patients. A similar approach was followed to identify allergens in cow milk proteins (Natale et al., 2004). Nonetheless, in this case, after the identification of the allergens with immunoblotting, they were separated with 2-DE, and the cow milk proteins and their isoforms were characterized with MALDI-TOF MS (Natale et al., 2004). The combination of immunoassays with MS has also shown great capabilities for the characterization of food allergens. Ig-E immunoblotting was used to reveal potential allergens in tomato fruits and seeds whereas a multidimensional protein fractionation strategy and LC-MS/MS were used for the precise molecular characterization of the allergens (Bassler et al., 2009). In the study of food allergies, surface-enhanced laser desorption/ionization (SELDI) microarrays have been demonstrated to be effective tools for the detection of new food allergens, as effective as traditional Western blot, but faster. This procedure was employed to identify and characterize allergens in banana (Hsieh et al., 2002). Nevertheless it is also useful to detect known allergens, such as lysozyme in cheeses (Dragoni et al., 2010).

\section{Detection of pathogens and toxins.}

Detection of pathogens, toxins, and sub-products in food spoiled by microorganisms is a relevant aspect of food safety. GC-MS has been used to profile metabolites from food products to identify volatile compounds related to a particular microbial contamination. After this metabolomic approach, volatiles were identified in contaminated meat samples that were generated only when a particular microorganism was present (Ercolini et al., 2009). More than 100 metabolites were correctly identified in the different contaminated meat samples, and their relationships were studied. It was also 
found that, not only some volatiles appeared as a result of their release as a consequence of the growth of a particular bacteria, but also that the volatile compounds profile changed significantly between the contaminated and control meat samples (Ercolini et al., 2009). This basic approach can be also combined with chemometric strategies in order to correctly analyze the results obtained from the metabolic profiling. In fact, principal component analysis (PCA) was used to identify important regions in the GCMS chromatogram that resulted from the profile of volatile organic compounds from natural spoiled pork and pork contaminated with Salmonella typhimurium (Xu et al., 2010). Once the important regions in the chromatogram were identified, peak deconvolution was applied in order to increase the certainty of the peak identification. Thanks to this combination of profiling plus chemometrics, a clear distinction between the two groups of samples was possible (Xu et al., 2010). MS has been also used to directly identify microorganisms or even strains that might contaminate food, through the application of proteomics tools. MALDI-TOF-MS has been applied to identify and characterize low molecular weight proteins extracted from intact bacterial cells (Bohme et al., 2010) or even ribosomal proteins (Barbuddhee et al., 2008). From reference MS fingerprints (from 2000 to $10000 \mathrm{Da}$ ), it was possible to differentiate among the different bacterial species and genera under study (Bohme et al., 2010). Interestingly, the statistical study of the phylo-proteomic relationships based on the MS data provided the same clustering than the phylogenetic analysis based on the 16S rRNA gene; those data demonstrated the usefulness and applicability of the procedure. Besides, the comparison of the reference profiles and the profiles obtained from seafood samples allowed the adequate application of this methodology to identify unknown bacterial strains (Bohme et al., 2010). In Figure 4, examples of the used reference profiles are depicted. Pathogens have also been identified based on the characterization of 
distinctive peptides contained in proteolytic digests with a separation technique (CE) coupled to tandem MS (Hu et al., 2006). The determination of the amount of microorganisms present in a sample used ICP-MS with an immunoassay with antibodyconjugated gold nanoparticles (Li et al., 2010). Quantitative determination of E. coli used the direct determination of $\mathrm{Au}$ at $\mathrm{m} / \mathrm{z}$ 197, thanks to the previous interaction between the antibody-conjugated gold nanoparticles and Escherichia coli O157:H7 cells (Li et al. 2010).

Similar strategies to those previously described to detect contaminants are usually employed to detect toxins in foods. These strategies include the use of an extraction mechanism, followed by a high-resolution separation step coupled to MS. The QuEChERS method has been frequently applied for the simultaneous extraction and analysis of relatively wide groups of toxins (Rasmussen et al., 2010; Zachariasova et al., 2010). Triple quadrupole analyzers provide an LOD of few $\mu \mathrm{g} \mathrm{kg}^{-1}$ (Rasmussenet al., 2010), whereas UPLC speeds-up the separation method (Zachariasova et al., 2010). Moreover, the coupling of UPLC to high resolution mass spectrometers, such as orbitrap, significantly enhanced the accuracy of the determination, and maintained comparable LOD to those obtained with a TOF-MS analyzer. However, the use of the orbitrap minimized the sample treatment and handling, and increased the sample throughput (Zachariasova et al., 2010). It is interesting to mention that, even if the mass accuracy provided by orbitrap analyzers is one order of magnitude higher than most common tandem mass analyzers, it has not been possible so far to reach the number of identification points required for the current EU legislation for the analysis of mycotoxins (Comission decision 2002/657/EC), because accuracy is not considered in the identification points system implemented by the EU (Comission decision 
2002/657/EC). Thus, unless the existing criteria evolve towards higher mass accuracy, the full potential of these MS instruments will not be completely helpful for regulatory food control.

\section{Food quality and geographical origin assessment.}

In terms of food quality, metabolite fingerprinting with separation techniques coupled to MS provide valuable information on the precise composition of food products that can be directly correlated to their quality. Comprehensive GC-MS fingerprinted the volatile fraction of roasted hazelnuts (Cordero et al., 2010), whereas the corresponding volatile fingerprint of beer was obtained with GC-TOF-MS (Cajka et al., 2010). LC-MS was used to profile the flavonols and anthocyanins in grapes (Mattivi et al., 2006), and direct-flow injection MS-based profiling has also been used for beer (Araujo et al. 2005) and potato samples (Beckmann et al., 2007). MS-based metabolite profiling determined the changes during germination of rice (Shu et al., 2008), characterized milks according to their production conditions (Fernandez et al., 2003), assessed the possible impact of the different wheat-farming systems (Zorb et al., 2006), as well as to reveal the effects of pre-storage UV irradiation in apples that can be also correlated to their quality (Rudell, Mettheis \& Curry, 2008).

A good example of the use of Foodomics for food quality issues is the development of food metabolomes through the implementation of specific metabolites databases. Tomato metabolome has been collected as a database with the information provided by LC-MS (Moco et al., 2006). The human milk glycome was also determined by combining LC-MS with stand-alone high-resolution MS (MALDI-FT-ICR-MS) to 
identify with higher accuracy the oligosaccharides contained in human milk (Ninonuevo et al., 2006).

A quality characteristic that makes so valuable the olive oil is its triacylglycerol composition, and therefore, fatty acid composition. Direct analysis in real time (DART) coupled to TOF-MS was employed to obtain the comprehensive profiling of triacylglycerols from olive oil (Vaclavik et al., 2009). The implementation of this methodology, together with linear discriminant analysis, not only differentiated among diverse olive oil-related products (extra virgin olive oil, olive oil pomace, olive oil), but also emerged as a good alternative to reveal extra virgin olive oil adulteration with hazelnut oil - a commonly employed adulterant (Vaclavik et al., 2009). On the other hand, the determination of fatty acids from olive oil with direct infusion MS also permitted the prediction of the genetic variety used to obtain different extra virgin olive oils (Lerma-Garcia et al., 2008; Gomez-Ariza, Arias-Borego \& Garcia-Barrera, 2006). Considering the low polarity of these compounds, MALDI-TOF MS have been also demonstrated as a very useful analytical approach for lipidomics studies (Fuchs \& Schiller, 2009). Likewise, the multiple detection of other food components, for instance polyphenols, based on the use of direct MS can be employed to establish metabolite fingerprints useful for food quality avoiding the coupling to a separation technique (Fulcrand et al., 2008).

Proteomics approaches have been also applied to assess food quality because protein profiling can give useful information on food composition, origin, or adulteration (Carbonaro, 2004). Wine proteins are very important to the wine quality because they affect taste, clarity, and stability. To better-know the proteins present in 
wine, as well as their possible functions, an LC-MS/MS method was used (Kwon, 2004). The protein profiling of a white wine revealed the existence of 20 proteins in the samples. Interestingly, only 5 of them were directly derived from the grape. Twelve additional proteins belonged to yeast, two from bacteria, and one from fungi. The results indicated the possibility of contaminations due to infections on the vineyard or even improper handing during the harvest and winemaking procedures (Kwon, 2004). Moreover, this type of applications might open new possibilities to detect adulterations if the protein profile could be correlated to the corresponding grape variety. The use of multivariate analysis was useful to analyze the data from the MALDI-TOF-MS analysis of different wheat proteins previously separated with 2-D PAGE (Gottlieb et al., 2002). Gliadin is a protein from the wheat gluten complex that determines whether the crop can be employed or not in breadmaking. The PCA of the MS proteomic data differentiated wheat varieties according to this quality parameter (Gottlieb et al., 2002); that study demonstrated the usefulness of proteomic approaches combined with chemometrics for food quality. Also, peptides naturally present in some foods are of importance to food quality, considering the bioactive activities that might have, as well as those that could be formed during the digestion. Different proteomic studies have been developed to identify this kind of bioactive peptides (Gomez-Ruiz et al., 2006; Gagriaire et al., 2009).

Geographical origin is one of the most-important quality parameters for some foods. The high added value that a particular origin might have compared to others has brought about the protected denomination of origin of some foods. This importance of the foods' origin has caused the appearance of frauds or adulterations with similar lessvaluable products. In this sense, the assessment of the origin authenticity of food products is of great importance for food quality. However, one of the most important 
difficulties to carry out geographical certification is the appropriate selection of suitable markers. MS-based techniques combined with statistical analysis can effectively help to solve this limitation. One of the most-employed approaches is ICP-MS for the elemental fingerprint combined with chemometrics, mainly multivariate analysis techniques (i.e., principal component, canonical discriminant, linear discriminant analysis) for the classification of samples with different geographical origin. This strategy has been applied, for instance, to assess the authenticity of paprika (Brunner et al., 2010), olive oil (Benincasa et al., 2007), honey (Chudzinska \& Baralkiewicz, 2010) and tomato products (Lo Feudo et al., 2010). Other possibility for geographical discrimination of foods seems to rely on the fingerprinting of metabolites. The determination of the volatiles present in honey (Mannas \& Altug, 2007) or coffee (Risicevic, Carasek \& Pawliszyn, 2008) are two examples of this kind of applications. In fact, the combination of head space, solid phase microextraction, and GC-TOF-MS isolated and identified more than 100 volatile compounds in coffee samples, with different experimental designs to determine the extraction conditions that provided a higher number of volatiles extracted. The complete subsequent analysis, in $8 \mathrm{~min}$, attained semiquantitative results that were submitted to PCA statistical evaluation to establish the geographical discriminations (Risticevic, Carasek \& Pawliszyn, 2008).

Another metabolite-based option with MS, is the use of stable isotope ratio MS (IRMS). This technique detects small differences in stable isotopes that can be correlated to different origins or even to adulterations of products. Besides, the combination of this technique with GC allows the isotopic analysis of each separated compound. The effectiveness of this technique to detect differences in the isotopic 
carbon composition for the authentication of mandarin essential oils has been recently demonstrated (Schiplilliti et al., 2010).

The exhaustive study of food proteins and their relationships is also useful to detect food-adulteration. Protein profiling with MS can search for biomarkers that permit the characterization of food samples according to their origin. Levels of 1049 proteins were recorded in organic and conventional wheat of different seasons (Zorb, Betsche \& Langerkamper, 2009). After statistical analysis, 25 proteins possessed different levels in the two wheat classes. After considering the seasonal influence, 16 were selected as diagnostic proteins, and were identified with MALDI-TOF-MS after 2DE. The determination of these 16 proteins could authenticate organic wheat (Zorb, Betsche \& Langerkamper, 2009). A quite similar approach with 2-DE and MALDITOF-MS was applied to fish (Mazzeo et al., 2010) and shrimp authentication (Ortea, Cañas \& Gallardo, 2009). In both cases, precise biomarkers were found. In other interesting research, Wang et al. developed a fast method for the fingerprinting and barcoding of honey proteins with a MALDI-TOF mass spectrometer (Wang et al., 2009). Starting from the information collected by MS, protein fingerprints were generated that were translated into a database library of spectral barcodes. Figure 5 shows the procedure. Once the library was acquired, the authentication confirmation was performed in honey samples through pattern matching.

The study of proteins can be also useful to detect adulterations in food products. The aim of these applications usually is the detection of proteins that are not a part of the proteome of the studied product. An example of this approach was the development of an untargeted LC-QTOF-MS method for the proteins analysis in skimmed milk 
powder (Cordawener et al., 2009). The significantly lower price of other vegetableprotein preparations induces the partial adulteration of the dairy product with soy or pea proteins. It was demonstrated that this procedure detected the presence of adulterations in the milk powder based on differential peptide profiling.

\section{Food traceability.}

Foodomics plays an important role for food traceability in which MS-based metabolomics and proteomics are applied. As an example, the profiling of metabolites can be used not only to determine the origin, but also to obtain the traceability of a given food, that is, to precisely know all the different manufacture steps to which a particular food has been submitted. Thus, powerful separation techniques such as comprehensive 2D GC has been combined with high-resolution MS (TOF-MS) to profile monoterpenoids in grapes (Rocha et al., 2007). This profiling allowed knowing the precise monoterpenoid composition of the different varieties of grapes, and their application allowed the traceability of the products directly derived from these grapes, such as must and wines. A similar strategy was devised aimed to the correct origin traceability of honey samples (Cjaka et al., 2009). In that case, artificial neural networks were used in the chemometric calculations in order to obtain a correct correlation between the volatiles profile and the origin of the honey.

The attainment of peptide profiles with MALDI-TOF-MS has been proposed as another useful tool for food traceability (Chambery et al., 2009). Barcodes derived from these MS data were suggested for the adequate establishment of food traceability.

\section{B. MS-based methodologies to develop and characterize transgenic foods.}


The rapid progress of recombinant DNA technology (or genetic engineering) has opened new prospects in the development of novel foods and food ingredients (Petit et al., 2007). Recombinant DNA allows selected individual gene sequences to be transferred from an organism into another and also between non-related species. The organisms derived from recombinant DNA technology are termed genetically modified organisms (GMOs). A transgenic food is a food that is derived from or contains GMOs.

Owing to the complexity that entails the compositional study of a biological system such as GMO, the study of substantial equivalence (OECD, 1993) as well as the detection of any unintended effects (Ioset et al., 2007) should be approached with advanced profiling techniques, with the potential to extend the breadth of comparative analyses (EFSA, 2006). However, there is no single technique currently available to acquire significant amounts of data in a single experimental analysis to detect all compounds found in GMOs or any other organism (Saito \& Matsuda, 2010). In consequence, multiple analytical techniques have to be combined to improve analytical coverage of proteins and metabolites.

\section{Proteomics.}

MS-based proteomic analysis has become a key technology for the characterization of proteins and peptides in transgenic food and food ingredients. Based on the so-called bottom-up approach, two-dimensional gel electrophoresis (2-DE), followed with image analysis, and MS (typically MALDI-TOF-MS) or different variants of LC-MS, is the most commonly used analytical methodology to study differentially expressed proteins in GMOs (García-Cañas et al., in press). 2-DE provides the highest protein-resolution capacity with a low-instrumentation cost. This strategy has been used to compare 
protein profiles of GM tomatoes (Corpillo et al., 2004; Di Carli et al., 2009), maize (Albo et al., 2007; Zolla et al., 2008), wheat (Di Luccia et al., 2005; Scossa et al., 2008), Arabidopsis thaliana (Ren et al., 2009, Ruebelt et al., 2006a; 2006b; 2006c), and potatoes (Careri et al., 2003; Lehesranta et al., 2005) versus their corresponding unmodified lines.

In 2-DE, besides the technical limitations to separate highly hydrophobic, extreme isoelectric point, or high molecular weight (MW) proteins, one of the major sources of error is the gel-to-gel variation that makes difficult an exact match of spots in the image-analysis process. Different approaches, such as the use of multi-gel systems, have been investigated to improve gel-to-gel reproducibility (Zhan \& Desiderio, 2003). Recently, Brandao et al. (Brandao, Barbosa \& Arruda, 2010) used a strictly controlled routine for image analysis of 2-D gels for the comparative analysis of GM soybean proteome and the corresponding non-modified soybean line. Eight out of ten protein spots that showed changes in expression were characterized and identified with MALDI-QTOF-MS as storage proteins, actin, and a sucrose-binding protein. Also, DIGE can help to circumvent the gel-to-gel variance problem for comparative proteomics by loading different samples labeled with ultrahigh-sensitive fluorescent dyes, typically Cy5 and Cy3, in the same gel (Timms \& Cramer, 2008). Islam et al. applied DIGE to compare the proteomes of wild-type cultivars with two GM pea lines that express $\alpha$-amylase inhibitor from the common bean (Islam et al., 2009). Proteins from individual excised spots were digested with trypsin, and the peptides were analyzed with LC-ESI-QTOF-MS. Approximately 600 proteins with MW ranging from 15 to $100 \mathrm{kDa}$ and pIs between 3 and 10 were resolved in the gels. In that study, the gel images for the analysis of one of the GM peas displayed 66 spots that showed 
significant changes. The identification of some of the spots revealed alterations in seed storage proteins-

An LC-ESI-IT-MS has been recently developed to characterize maize cultivars from different origins (García-López, Garcia-Cañas \& Marina, 2009). The analyses revealed MS spectral signals that seemed to be characteristic of cultivars with a same geographical origin. A CE-ESI-MS was applied for the analysis of an intact zein-protein fraction from three different GM maize cultivars and their corresponding isogenic lines (Erny et al., 2008). A comparative study of two different mass analyzers, namely, TOF and IT, was carried out. Results showed similar sensitivity and repeatability for both instruments; however, CE-ESI-TOF-MS provided a better number of identified proteins. A comparison of the protein profiles obtained with CE-ESI-TOF-MS did not show any significant differences between the GM lines and their non-modified counterpart. Recently, a novel CE-ESI-TOF-MS profiling method, based on shotgunproteomics strategy, was developed to investigate any unintended effects in GM soybeans (Simó et al., 2010). With this method, 151 peptides were obtained for each soybean line (see Figure 6); however, no differences between GM soybean and its conventional counterpart were found.

\section{Metabolomics.}

The use of GC-MS to study the metabolome of GMOs has been one of the most popular strategies reported in the literature because the technique provides high separation efficiency and reproducibility, and it allows the analysis of primary metabolites such as amino acids, organic acids, and sugars with chemical derivatization. In one of the first works on this topic, Roessner et al. applied GC coupled to a quadrupole mass 
spectrometer to characterize the metabolic composition of transgenic potato tubers with modified sugar or starch metabolism (Roessner et al., 2000). Identification of the compounds was carried out by spectra comparison with commercial mass spectrum libraries plus the injection of standard compounds. Quantitation of metabolites based on this methodology provided data comparable to those obtained using enzymatically linked photometric assays or HPLC analysis. The identification of 77 out of 150 compounds detected with GC-MS provided valuable information on the altered metabolic pathways, and unexpected changes in the levels of some compounds in the transgenic tubers. In a separate report, the GC-MS analysis of GM potato tubers with altered sucrose catabolism indicated an increased level of amino acids (Roessner, Willmitzer \& Fernie, 2001). The suitability of GC-MS in combination with data-mining tools (e.g., PCA and hierarchical clustering) to discover differences that enable the discrimination of the transgenic potato and tomato lines from the respective nonmodified lines, has been also demonstrated in further researches (Roessner et al., 2001; Roessner-Tunali et al., 2003). GC-MS is a valuable tool to profile aroma compounds in transgenic fruits and vegetables. Malowicki, Martin \& Qian applied GC-MS to investigate the volatile fraction of GM raspberries with added resistance to virus attack not observing any significant differences between the GM line and the wild-type (Malowicki, Martin \& Qian, 2008). Similarly, the qualitative and quantitative composition of the aroma among four lines of GM cucumber that overexpress thaumatin II gene and their unmodified lines were also investigated with GC-MS (Zawirska-Wojtasiak et al., 2009).

The combined use of supercritical fluid extraction (SFE) and GC-MS has been used to investigate any unintended effects in GMOs (Bernal et al., 2005). Profiling and 
quantification of the extracts detected differences in the amino acid content by the comparison of five different transgenic lines with their corresponding isogenic lines grown under the same conditions. In another research, the relative concentrations of 44 fatty acids (saturated and unsaturated fatty acids, including cis/trans isomers and minor fatty acids) of GM maize and soybean seeds have been compared with GC-MS with those of isogenic lines grown in the same conditions (Jimenez et al., 2009).

Catchpole et al. used two MS-based techniques to obtain complementary data on the compositional similarities/differences between transgenic potato designed to contain high levels of inulin-type fructans and its conventional counterpart (Catchpole et al., 2005). Initially, flow-injection analysis (FIA) ESI-MS was used to analyze 600 potato extracts. Data sets were analyzed with PCA to identify top-ranking ions for genotype identification. Further GC-TOF-MS profiling of more than 2000 tuber samples provided complementary data that covered 242 individual metabolites (90 positively identified, 89 assigned to a specific metabolite class, and 73 unknown). In a further research, Zhou et al. have used GC-MS exclusively used to identify certain important compounds after GC- flame ionization detection (FID) profiling of insect-resistant GM rice (Zhou et al., 2009).

Shin et al. used LC-MS to study transgenic rice with altered production of various flavonoids (Shin et al., 2006). Similarly, the study of flavonoid profiles in pathogen-resistant GM wheat was investigated with LC-MS (Ioset et al., 2007). In this case, flavonoids were extracted with SPE and analyzed with LC-IT-MS with two different ionization sources-ESI and APCI. Additional LC-MS/MS experiments differentiated between C-glycoside flavonoids and O-glycoside analogs. A novel LC- 
MS method has been developed for the profiling of stilbenes, a specific class of polyphenols, in transgenic tomato that overexpress a grapevine gene that encoded the enzyme stilbene synthase (Nicoletti et al., 2007). With this methodology, differences in the concentration of rutin, naringenin, and chlorogenic acid were detected when transgenic tomatoes were compared to the control tomato lines. The combined use of LC-MS with GC-MS improved the description of the metabolome status of GMOs. In this regard, differences in some phenolic compounds and volatile secondary metabolites that belong to the classes of monoterpenes, C12-norisoprenoids, and shikimates were detected with LC-ESI-IT-MS and GC-MS for the comparative analysis of GM grapevine lines with the unmodified control (Tesniere et al., 2006).

Although reversed-phase is the most frequent mode used in LC-MS metabolite profiling in GMO analysis, other suitable modes are useful. For example, the levels of the major carbon metabolites in transgenic rice that overexpress ADP-glucose pyrophosphorylase have been determined with a HILIC (hydrophilic interaction liquid chromatography) phase for the separation in LC-ESI-MS/MS (Nagai et al., 2009). In a recent paper, Matsuda et al. analyzed different plant tissues of GM rice with LC-ESI-QMS. Metabolic profile data were analyzed with three different statistical methods (i.e., independent component analysis (ICA), correlation analysis, and Student's t-test) to determine the peaks that characterize the difference between GM rice and the unmodified counterpart (Matsuda et al., 2010). Complementary LC-MS/MS analysis identified 26 peaks selected after the statistical treatment. Results obtained in the study also indicated that the concentration of Trp changed in a time-dependent manner to show a tissue-dependent profile of accumulation. 
The potential of CE-MS for metabolic profiling of GMOs has already been demonstrated to study GM rice (Takahashi et al., 2006). Identification of chemical compounds was performed by comparison of their $\mathrm{m} / \mathrm{z}$ and migration times with standard metabolites. Novel methods, based on CE-MS for metabolite profiling of GM maize and soybean, have been developed recently (Levandi et al., 2008; Garcia-Villalba et al., 2008). Thus, CE-ESI-TOF-MS was used to determine statistically significant differences in the metabolic profile of varieties of conventional and insect-resistant GM maize (Levandi et al., 2008). A similar CE-ESI-TOF-MS methodology was developed for the comparative analysis of metabolic profiles from transgenic soybean (glyphosate resistant) and its corresponding unmodified parental line (García-Villalba et al., 2008). In that study, over 45 different metabolites, including isoflavones, amino acids, and carboxylic acids were identified. Recently, Giuffrida et al. developed a chiral CE-ESITOF-MS method to study differences in the chiral amino acid profile among varieties of conventional and transgenic soybean modified to be tolerant to glyphosate herbicide (Giuffrida et al., 2009). In that research, the obtained D/L-amino acid profiles were very similar for conventional and GM soybean.

FT-ICR-MS has already been used as a powerful analytical platform for metabolomic studies in GMOs (Aharoni et al., 2002; Takahashi et al., 2005; Mungur et al., 2005). Owing to its excellent mass resolution (greater than 100,000) and accuracy (sub-ppm), FT-ICR-MS enables molecular formula determination from a vast number of different compounds to be determined in direct-infusion analyses of complex samples without any previous chromatographic or electrophoretic separation and/or derivatization reaction. However, poor ionization of interesting analytes might occur due to matrix effects during direct infusion. In addition, FT-ICR-MS offers moderate 
sensitivity and quantitative capabilities. In a recent research, CE-TOF-MS and FT-ICRMS were used for the metabolomic profiling of six varieties of maize, three GM insectresistant lines, and their corresponding isogenic lines (Leon et al., 2009). The FT-ICRMS data obtained in positive and negative ESI mode were both uploaded into a MassTRIX server (Suhre \& Schmitt-Kopplin, 2008) in order to identify maize-specific metabolites annotated in the KEGG (Kyoto encyclopedia of genes and genomes) database. Despite the mentioned good mass resolution and accuracy of the technique, certain compounds could not be unequivocally identified, because FT-ICR-MS cannot differentiate isomers that have the same molecular formula, so that migration time, electrophoretical mobilities, and $\mathrm{m} / \mathrm{z}$ values provided by CE-TOF-MS were used to confirm the identity of various compounds.

\section{Foodomics in nutrition and health research. MS-based "omics" approaches in Nutrigenomics, Nutriproteomics, and Nutrimetabolomics.}

Nutrigenomics is a branch of Foodomics that focuses on the study of the effects of foods and food constituents on gene expression. Nutrigenomics studies the impact of specific nutrients on health through the expression of genetic information by the integration of "omics" technologies such as transcriptomics, proteomics, and metabolomics. MS-based techniques were applied for proteomics and metabolomics, whereas transcriptomics studies the mRNA expression of genes with microarray technology and techniques based on DNA sequencing.

In Foodomics, to carry out a comprehensive elucidation of the mechanisms of action of natural compounds, specific nutrients or diets, in-vitro assays or animal models are mainly used because (i) they are genetically homogeneous within a 
particular assay or animal model, and (ii) environmental factors can be controlled. Moreover, these assays allow the study of certain tissues that would be not possible to obtain from humans. On the other hand, the main difficulty on the study of diets is the simultaneous presence of a variety of nutrients, with diverse chemical structures, that can have numerous targets with different affinities and specificities. Ideally, the final demonstration on the bioactivity of a given food constituent should be probed by Foodomics based on a global omics study of the biological samples generated during a clinical trial.

From a proteomics point of view, in order to glean an insight on the effect of specific natural compounds, nutrients, or diet on the proteome of organisms, tissues, or cells, comparative proteomics strategies are mainly used. Most of them are based on a bottom-up proteomic approach; more precisely, in a combination of classical 2-DE separation of proteins and MS detection of the in-gel digested proteins. It is interesting to mention that there are still rather limited studies on the effect of specific natural compounds, nutrients, or diet on the proteome of organisms, tissues, or cells; the number of review papers on this topic is higher than the number of research papers (de Roos \& McArdle, 2008). Table 2 shows some representative Nutrigenomics applications that use MS-based proteomics. For instance, dietary antioxidants have been studied as candidate chemopreventive agents against carcinogenesis and inhibition of tumor progression. Proteomics is a key tool to explore the molecular mechanisms involved in their anticancer activity. In a recent research, dietary supplementation with three combined micronutrients (vitamin E, selenium, and lycopene) was studied by Cervi et al. of which vitamin $\mathrm{E}$ and lycopene have recognized antioxidant activity in mice (Cervi et al., 2010). In this study a first expression difference mapping using the 
purified peptide-containing fraction from mice plasma was carried out using SELDITOF for the selection of candidate serum biomarkers of vitamin E, selenium, and lycopene-supplementation. The same purified peptide-containing fraction was then fractionated by SDS/PAGE. The selected protein-containing band was in-gel digested and analyzed by LC-MS/MS for peptide identification. It was observed that combinations of micronutrients showed synergistic effects as preventative therapy for the progression of prostate cancer in transgenic mice model systems (Cervi et al., 2010).

At present, isoflavones are used as functional ingredients in a wide range of novel foods because there is considerable interest in their potential health benefits. Isoflavones are complex molecules with multiple biological activities, including prevention of cardiovascular diseases, neurodegenerative diseases, osteoporosis, cancer, obesity, or aging. Rowell, Carpenter \& Lamartiniere demonstrated for the first time the usefulness of proteomics for the discovery of novel pathways that might be involved in cancer prevention by isoflavones (Rowell, Carpenter \& Lamartiniere, 2005). For a better understanding of the pathways for the metabolism of isoflavones, a liver proteome was studied on rats treated with isoflavone rich extracts of red clover. For this pursose, total liver proteins were separated by 2-DE, and proteins which showed differences in their intensities were identified by MALDI-TOF-MS. A significant upregulation of 3-hydroxy-3-methylglutarly-CoAsynthase, and a down-regulation in peroxiredoxin 4 and 3-a-hydroxysteroid dehydrogenase were observed upon red clover treatment as compared to untreated controls, what support the potential of isoflavone rich red clover extract to modulate the lipid metabolism (Pakalapati et al., 2009). 
Polyphenols, abundant in plant-derived foods particularly fruits, seeds, and leaves, and their beneficial effect for disease prevention have also been studied from a proteomic point of view. Proteomic results revealed the positive effects of red wine polyphenol compounds for stroke protection either as prevention or treatment of the different phases of the disease (Ritz et al., 2008).

The antiobesity effect of capsaicin, a major ingredient in hot pepper, has also been studied in rats (Kim et al., 2010, Joo et al., 2010). Through the comparative proteome analysis of white adipose tissue, those authors identified proteins involved in lipid metabolism, redox processes, and signal and energy transduction to provide important information about the mechanism of the antiobesity effects of capsaicin.

Chronic alcohol consumption has been studied from a proteomic point of view (Fogle et al., 2010). Cleavable isotope coded affinity tags (ICAT) technology in combination with SDS/PAGE for protein fractionation and MALDI-TOF-MS of the resulting labelled peptides from the SDS/PAGE gel slices, was used to identify differentially deregulated proteins in the myocardium of rats fed with a diet that contained ethanol. In general, myofibrillar, sarcoplasmic, membrane-associated, and mitochondrial proteins in cardiac muscle were reduced after chronic ethanol administration. The effect of a Platycodi Radix extract supplemented in diet of alcoholexposed rats was studied by An et al. (An et al., 2009). Proteomic analysis revealed that 50 different proteins (involved with cytoskeleton regulation, signal transduction, cytokine, apoptosis, and reactive oxygen species metabolism) showed significant quantitative changes. After identification of these proteins, results suggested that the 
antioxidant activity associated to Platycodi Radix intake might play a protective role on liver tissues of chronically alcoholic rats.

The piglet was used as an animal model to study the therapeutic effect of $\mathrm{Zn}$ on intestinal function in neonates (Wang et al., 2009b). A zinc oxide-supplemented diet showed the beneficial alteration of intestinal proteins related to the regulation of oxidative stress, redox state, cell proliferation, and apoptosis processes. The effect of maternal fatty acid nutrition on the protein expression in the neonatal offspring liver in rats has also been studied using conventional proteomic approach combining 2-DE and MALDI-TOF MS (Novak et al., 2009). The study on the up- and down-regulated proteins revealed that early fatty acid nutrition impacts hepatic metabolic pathways relevant to luconeogenesis, redox balance, and nitric oxide signaling.

The discovery of nutritional biomarkers offers great potential to understand the relationship between diet and health. A proteomic study of the intake of selenomethylselenocysteine (SeMSeCys), a chemoprotective form of selenium, was carried out by Mahn et al. (Mahn, Toledo \& Ruz, 2009). Protein-expression patterns by 2-DE in blood plasma were studied in model rats treated with a different selenium dose (SeMSeCys or sodium selenate) and supplementation periods. Apolipoprotein E and transthyretin proteins were proposed as potential biomarkers of chemoprotective selenium intake.

Metabolic impact of flavonoid intake was studied with GC-MS. Sample preparation methods were optimized for metabolite extraction from several different biological matrices; i.e., urine, plasma, fecal samples, and in-vitro colonic fermentation 
models. The sample preparation and GC-MS methods were used to study the metabolic impact in urine samples after intake of cellulose capsules with a polyphenol-rich mix of red wine and red grape juice extracts. Multivariate data analysis based on orthogonal projection-discriminant analysis (OPLS-DA) was applied to determine any differences between control and intervention groups to obtain the clear classification that can be seen in Figure 7 (Grun et al., 2008).

Great advances have been achieved with LC-MS- and CE-MS-based approaches for metabolic profiling/fingerprinting (Klaus 2010, Ramautar, Somsen \& de Jong, 2009). Llorach-Asuncion et al. proposed the study of the metabolome modification before consumption of cocoa powder and during several periods after consumption with a combined partial least square discriminant analysis (PLS-DA) and two-way hierarchical clustering (two-wayHCA) to improve the analysis of the complex set of data obtained with HPLC-Q-TOF (Llorach-Asuncion et al., 2010).

\section{FOODOMICS, MS-BASED METHODOLOGIES, AND SYSTEMS BIOLOGY.}

MS-based strategies used in Foodomics have to face important difficulties derived, among others, from food complexity, the huge natural variability, the large number of different nutrients and bioactive food compounds, their very different concentrations, and the numerous targets with different affinities and specificities that they might have. In this context, proteomics and metabolomics (plus transcriptomics) represents powerful analytical platforms developed for the analysis of proteins and metabolites (plus gene expression). However, 'omics' platforms must be integrated in order to understand the 
biological meaning of the results on the investigated system (e.g., cell, tissue, organ) that give rise to the growth of a new discipline called Systems Biology (Hood et al., 2004). Thus, Systems Biology can be defined as an integrated approach to study biological systems, at the level of cells, organs, or organisms, by measuring and integrating genomic, proteomic, and metabolic data (Panagiotou \& Nielsen, 2009). Systems Biology approaches might encompass molecules, cells, organs, individuals, or even ecosystems, and it is regarded as an integrative approach of all information at the different levels of genomic expression (mRNA, protein, metabolite).

Although Systems Biology has been scarcely applied to Foodomics studies, its potential is underlined by its adoption by other disciplines. For instance, a Systems Biology approach has been applied to investigate carbohydrate metabolism in yeast (Weston \& Hood, 2004). In a recent research, Kohanski et al. used the context likelihood of relatedness (CLR) algorithm (gene network analysis) in combination with gene expression microarrays and Gene Ontology-based enrichment analysis to construct and filter gene connectivity maps of bacteria under antibiotic treatment (Kohanski et al., 2008). The gene networks were further enriched with data derived from antibiotic growth high-throughput screening to provide insight into the pathway whereby the antibiotic under study triggers its bactericide action.

Recently, Systems Biology has been applied to understand the complexity of the processes in the intestinal tract (dos Santos, Muller \& de Vos, 2010). This study is based on human adult microbiota characterization by deep metagenomic sequencing, identification of several hundreds of intestinal genomes at the sequence level, identification of the transcriptional response of the host and selected microbes in animal 
model systems and in humans, determination of the transcriptional response of the host to different diets in humans, germ-free and gene knockout animals, together with different metabolomics and proteomics studies. Based on these data, an integrated, modular modelling framework that cross-links top-down and bottom-up approaches for the various levels of biological organization is proposed to understand intestinal function (dos Santos, Muller \& de Vos, 2010).

D'Alessandro et al., have compiled and exhaustive list of 573 bovine milk proteins and elaborated the data using bioinformatic tools in order to retrieve relevant information about the functional role of bovine milk proteins (D'Alessandro, Zolla \& Scaloni, 2011). An interactomics approach was applied for the first time in a food matrix that allowed the integrated study of the individual pathways, networks, and ontologies depicted. Bovine milk interactome is expected to be refined in the future using quantitative methods in protein interaction studies,

\section{FUTURE TRENDS IN FOODOMICS.}

MS-based tools will have to overcome important limitations for optimal implementation in Foodomics in the non-distant future. In proteomics, MS as a stand-alone technique or combined with 2-DE, liquid chromatography, and capillary electrophoresis has become widespread. However, there is an evident need to develop improved or alternative technologies (e.g., protein microarrays) to become into a reality the routine analysis for proteome research, including improvements in the resolution of peptides to provide increased protein coverage. Separate from more-sophisticated sample treatments and separation techniques, MS will continue being essential for the systematic investigation in proteomics. In this sense, conventional mass spectrometers are replaced by the more 
sophisticated and compact mass spectrometers - most of them hybrid instruments in a combination of two or more analyzers. As can be deduced from the lower number of proteomic applications in Foodomics compared to the use of metabolomics-based approaches, it is expected that the application of these new instruments together with further technological innovations will help proteomic profiling to become a standard practice also in Foodomics. New applications of proteomics technologies are expected in the study of microbial flora in gut (Gilad et al., 2010) or on the use of functional proteomics in Foodomics (Schittmayer et al., 2009). As an example, although MS-based proteomics has proven to be a very useful tool for the identification, characterization, and detection of food allergens, still there are some issues that have not been successfully resolved, such as the development of MS-based methods for the simultaneous determination of multiple food allergens in food products and commodities.

Great advance is expected in metabolomics with the incorporation of new MS interfaces for which nearly no sample preparation is needed (Chen et al., 2006; Feng et al., 2008; Huang et al., 2007). Comprehensive multidimensional techniques, such as GCxGC or LCxLC, are also a revolutionary improvement in separation techniques that will be implemented in metabolomics studies in the near future. They might provide not only an enhanced resolution and a large increase in the peak number, but also an increase in selectivity and sensitivity in comparison with conventional separation techniques. As an example, comprehensive GCxGC coupled to TOF-MS is a promising tool for metabolic profiling (Pasikanti, Ho \& Chan, 2008). Also, capillary electrokinetic techniques and their coupling to mass spectrometry (CE and CE-MS) are ideal tools for metabolomics, due to their minimal sample-preparation requirements, wide range of 
applications, great efficiency and resolution, and low sample consumption. Although CE and CE-MS have not been widely used in Foodomics (Herrero et al. 2010), they have already been identified as a very promising tool for metabolomic studies (GarciaVillalba et al., 2008; Levandi et al., 2008; Oh et al., 2010). Interesting examples on the use of CE-MS in Foodomics can be found in very recent research, such as the study of substantial equivalence of transgenic and conventional soybean from their peptidic profiles with a shot-gun approach (Simó et al., 2010).

The challenge in the combination of Foodomics and Systems Biology is not only at the technological level, where, as mentioned above, great improvements are being made and expected in the 'omics' technologies, but also on the bioinformatics side (data processing, clustering, dynamics, or integration of the various 'omics' levels) that will have to progress for Systems Biology to demonstrate all its potential in the new Foodomics discipline (Gehlenborg et al., 2010). In this regard, it is also interesting to mention that the traditional medical world has often noted that, although many of the omics tools and Foodomics approaches provide academically interesting research (Breikers et al., 2006; Fardet et al., 2007; Griffiths \& Grant, 2006; Narasaka et al., 2006; Rezzi et al., 2007; Smolenski et al., 2007), they have not been translated to methods or approaches with medicinal impact and value because the data integration when dealing with such complex systems is not straightforward (Hirai et al., 2004; Schnackenberg et al., 2006). Thus, traditional medicine represents an important challenge for Systems Biology. A good example of the complexity that Systems Biology has to face in the Foodomics field is the study of the interplay of food, microbiota, and host related to intestinal functions that can be only understood from a systems perspective. The long-term goal is to understand how specific nutrients, diets, 
and environmental conditions influence cell and organ function, and how they thereby impact on health and disease. This systems knowledge will be pivotal for the development of rational intervention strategies for the prevention of diseases such as diabetes, metabolic syndrome, obesity, and inflammatory bowel diseases.

In the future, Foodomics approaches can help to overcome the important limitations detected by several regulatory institutions, including the European Food Safety Authority (EFSA), related to the controversial demonstration about the health claims on different functional foods and food ingredients. Moreover, this approach can be extended to better prove (or not) the health claims that link health benefits to many other different compounds, most of them rejected by EFSA so far. In this regard, it has been mentioned that it is probably too early to conclude on the value of many substances for health. Thus, Foodomics could help to overcome the main limitations detected by EFSA to reject these proposals, namely: lack of information to identify the substance on which the claim is based; lack of evidence that the claimed effect is indeed beneficial to the maintenance or improvement of the functions of the body; lack of human studies with reliable measures of the claimed health benefit.

This knowledge can be better generated with multidisciplinary approaches that consider international consortia and working on Foodomics based on extensive populations. Foodomics can also be important in terms of public health by considering two different approaches: at short term, involves the clinical application to treat metabolic alterations such as diabetes, and at long term, more related to the public primary prevention-that means, to inhibit the development of disease before it occurs. It 
is clear that MS-based strategies will play a definitive role to solve these huge challenges in the new Foodomics field.

\section{ACKNOWLEDGMENTS}

M.H. would like to thank MICINN for his "Ramón y Cajal" contract. This work was supported by Projects AGL2008-05108-C03-01 and CONSOLIDER INGENIO 2010 CSD2007-00063 FUN-C-FOOD (Ministerio de Educación y Ciencia). 


\section{REFERENCES}

Aharoni A, De Vos CHR, Verhoeven HA., Maliepaard CA., Kruppa G, Bino R, Goodenowe DB. 2002. Nontargeted metabolome analysis by use of Fourier Transform Ion Cyclotron Mass Spectrometry. OMICS 6:217-234.

Albo AG, Mila S, Digilio G, Motto M, Aime S, Corpillo D. 2007. Proteomic analysis of a genetically modified maize flour carrying Cry1Ab gene and comparison to the corresponding wild-type. Maydica 52:443-455.

An JH, Kim DS, Lee YH, Ho JN, Kim HK, Kang OJ, Shin IS, Cho HY. 2009. Proteomic analysis of the protective effects of Platycodi Radix in liver of chronically alcoholic rats. J Med Food 12:1190-1198.

Araujo AS, da Rocha LL, Tomzela Dm, Sawaya ACHF, Almeida RR, Catharino RR, Eberlin MN. 2005. Electrospray ionization mass spectrometry fingerprinting of beer. and potato samples. Analyst 130:884-889.

Banerjee K, Oulkar DP, PAtil SB, Patil SH, Dasgupta S, Savant R, Adsule PG. 2008. Single-laboratory validation and uncertainty analysis of 82 pesticides determined in pomegranate, apple, and orange by ethyl acetate extraction and liquid chromatography/tandem mass spectrometry. J AOAC Int 91:1435-1445.

Barbuddhee SB, Maier T, Schwarz G, Kostrzewa M, Hof H, Domann E, Chakraborty T, Hain T. 2008. Rapid identification of typing of Listeria species by matrix-assisted laser desorption ionization-time of flight mass spectrometry. Appl Environ Microbiol 74:5402-5407.

Bassler OY, Weiss J, Wienkoop S, Lehmann K, Scheler C, Dolle S, Schwarz D, Franken P,George E, Worm M, Weckwerth W. 2009. Evidence for novel tomato seed allergens: IgE-reactive legumin and vicilin proteins identified by multidimensional 
fractionation-mass spectrometry and in silico epitope modelling. J Proteome Res 8:1111-1122.

Beckmann M, Enot DP, Overy DP, Draper J. 2007. Representation, comparison, and interpretation of metabolome fingerprint data for total composition analysis and quality trait investigation in potato cultivars. J Agric Food Chem 55:3444-3451.

Benincasa C, Lewis J, Perri E, Sindona G, Tagarelli A. 2007. Determination of trace element in Italian virgin olive oils and their characterization according to geographical origin by statistical analysis. Anal Chim Acta 585:366-370.

Bernal JL, Nozal MJ, Toribio L, Diego C, Mayo R, Maestre R. 2005. Use of supercritical fluid extraction and gas chromatography-mass spectrometry to obtain amino acid profiles from several genetically modified varieties of maize and soybean. $\mathbf{J}$ Chromatogr A 1192:266-272.

Bohm BA, Stachel CS, Gowik P. 2009. Multi-method for the determination of antibiotics of different substance groups in milk and validation in accordance with Commission Decision 2002/657/EC. J Chromatogr A 1216:8217-8223.

Bohme K, Fernandez-No IC, Barros-Velazquez J, Gallardo JM, Calo-Mata P, Cañas B. 2010. Species differentiation of seafood spoilage and pathogenic gram-egative bacteria my MALDI-TOF mass fingerprinting. J Proteome Res 9:3169-3183.

Brandao AR, Barbosa HS, Arruda MAZ. 2010. Image analysis of two-dimensional gel electrophoresis for comparative proteomics of transgenic and non-transgenic soybean seeds. J Proteomics 73:1433-1440.

Breikers G, van Breda SG, Bouwman FG, van Herwijnen MH, Renes J, Mariman EC, Kleinjans JC, van Delft JH. 2006. Potential protein markers for nutritional health effects on colorectal cancer in the mouse as revealed by proteomics analysis. Proteomics 6:2844-2852 
Brown SC, Kruppa G, Dasseux JL. 2005. Metabolomics applications of FT-ICR mass spectrometry. Mass Spectrom Rev 24:223-231.

Bruce SJ, Tavazzi I, Parisod V, Rezzi S, Kochhar S, Guy PA. 2009. Investigation of human blood plasma sample preparation for performing metabolomics using ultrahigh performance liquid chromatography/mass spectrometry. Anal Chem 81:3285-3296.

Brunner M, Katona R, Stefanka Z, Prohanska T. 2010. Determination of the geographical origin of processed spice using multielement and isotopic pattern on the example of Szegedi paprika. Eur Food Res Technol 231:623-634.

Cajka T, Hajslova J, Pudil F, Riddellova K. 2009. Traceability of honey origin based on volatiles pattern processing by artificial neural networks. J Chromatogr A 1216:14681462.

Cajka T, Riddellova K, Tomaniova M, Hajslova J. 2010. Recognition of beer brand based on multivariate analysis of volatile fingerprint. J Chromatogr A 1217:4195-4203.

Carbonaro M. 2004. Proteomics: present and future in food quality evaluation. Trends Food Sci Technol 15:209-216.

Careri M, Costa A, Elviri L, Lagos JB, Magia A, Terenghi M, Cereti A, Garoffo LP. 2007. Use of specific peptide biomarkers for quantitative confirmation of hidden allergic peanut proteins Ara $\mathrm{h} 2$ and Ara $\mathrm{h} 3 / 4$ for food control by liquid chromatography-tandem mass spectrometry. Anal Bioanal Chem 389:1901-1907.

Careri M, Elviri L, Mangia A, Zagnoni I, Agrimonti C, Visioli G, Marmiroli N. 2003. Analysis of protein profiles of genetically modified potato tubers by matrix-assisted laser desorption/ionization time-of-flight mass spectrometry. Rapid Commun Mass Sp $17: 479-483$. 
Carretero V, Blasco C, Picó Y. 2008. Multi-class determination of antimicrobials in meat by pressurized liquid extraction and liquid chromatography-tandem mass spectrometry. J Chromatogr A 1209:162-173.

Catchpole GS, Beckmann M, Enot DP, Mondhe M, Zywicki B, Taylor J, Hardy N, Smith A, King RD, Kell DB, Fiehn O, Draper J. 2005. Hierarchical metabolomics demonstrates substantial compositional similarity between genetically modified and conventional potato crops. P Natl Acad Sci 102:14458-14462.

Cervera MI, Medina C, Portolés T, Pitarch E, Beltran J, Serrahima E, Pineda L, Muñoz G, Centrich F, Hernandez F. 2010. Multi-redidue determination of 130 multiclass pesticides in fruits and vegetables by gas chromatography coupled to triple quadrupole tandem mass spectrometry. Anal Bioanal Chem 397:2873-2891.

Cervi D, Pak B, Venier NA, Sugar LM, Nam RK, Fleshner NE, Klotz LH, Venkateswaran V. 2010. Micronutrients attenuate progression of prostate cancer by elevating the endogenous inhibitor of angiogenesis, Platelet Factor-4. BMC Cancer $10: 258$

Chaissaigne H, Norgaard JV, van Hengel AJ. 2007. Proteomics-based approach to detect and identify major allergens in processed peanuts by capillary LC-Q-TOF (MS/MS). J Agric Food Chem 55:4461-4473.

Chambery A, del Monaco G, Di Maro A Parente A. 2009. Peptide fingerprinting of high quality Campania white wines by MALDI-TOF mass spectrometry. Food Chem 113:1283-1289.

Chen CH. 2008. Review of a current role of mass spectrometry for proteome research. Anal Chim Acta 624:16-36.

Chen H, Pan Z, Talaty N, Raftery D, Cooks RG. 2006. Combining desorption electrospray ionization mass spectrometry and nuclear magnetic resonance for 
differential metabolomics without sample preparation. Rapid Commun Mass Spectrom 20:1577-1584.

Chudzinska M, Baralkiewicz D. 2010. Estimation of honey authenticity by multielements characteristics using inductively coupled plasma-mass spectrometry (ICP-MS) combined with chemometrics. Food Chem Toxicol 48:284-290.

Chung SWC, Chan BTP. 2010. Validation and use of a fast sample preparation method and liquid chromatography-tandem mass spectrometry in analysis of ultra-trace levels of 98 organophosphorus pesticide and carbamate residues in a total diet study involving diversified food types. J Chromartogr A 1217:4815-4824.

Cifuentes A. 2009. Food analysis and foodomics. J Chromatogr A 1216:7109-7110.

Cordawener JHG, Luykx DMAM, Frankhuizen R, Bremer MGEG, Hooijerink H, America AHP. 2009. Untargeted LC-Q-TOF mass spectrometry method for the detection of adulterations in skimmed-milk powder. J Sep Sci 32:1216-1223.

Cordero C, Liberto E, Bicchi C, Rubiolo P, Shieberle P, Reichenbach SE, Tao Q. 2010. Profiling food volatiles by comprehensive two-dimensional gas chromatography coupled with mass spectrometry: Advanced fingerprinting approaches for comparative analysis of the volatile fraction of roasted hazelnuts (Corylus avellana L.) from different origins. J Chromatogr A 1217:5848-5858.

Corpillo D, Gardini G, Vaira AM, Basso M, Aime S, Accotto GP, Fasano M. 2004. Proteomics as a tool to improve investigation of substantial equivalence in genetically modified organisms: The case of a virus-resistant tomato. Proteomics 4:193-200.

D'Alessandro A, Zolla L, Scaloni A. 2011. The bovine milk proteome: cherishing, nourishing and fostering molecular complexity. An interactomics and functional overview. Mol Biosyst. In press (DOI: 10.1039/c0mb00027b) 
Dagnac T, Garcia-Chao M, Pulleiro P, Garcia-Jares C, Llompart M. 2009. Dispersive solid-phase extraction followed by liquid chromatography-tandem mass spectrometry for the multi-residue analysis of pesticides in raw bovine milk. J Chromatogr A 1216:3702-37093.

Daniells S. 2010. EFSA's antioxidant rejections could be blessing in disguise. http://www.foodqualitynews.com/Legislation/EFSA-s-antioxidant-rejections-could-beblessing-in-disguise (accessed April 7, 2010).

de Roos B, McArdle HJ. 2008. Proteomics as a tool for the modelling of biological processes and biomarker development in nutrition research. Br J Nutr 99:S6-S71.

Dettmer K, Aronov PA, Hammock BD. 2007. Mass spectrometry-based metabolomics. Mass Spectrom Rev 26:51-78.

Di Carli M, Villani ME, Renzone G, Nardi L, Pasquo A, Franconi R, Scaloni A, Benvenuto E, Desiderio A. 2009. Leaf proteome analysis of transgenic plants expressing antiviral antibodies. J Proteome Res 8:838-848.

Di Luccia A, Lamacchia C, Fares C, Padalino L, Mamone G, La Gatta B, Gambacorta G, Faccia M, Di Fonzo N., La Notte E. 2005. A proteomic approach to study protein variation in GM durum wheat in relation to technological properties of semolina. Ann Chim-Rome 95:405-414.

dos Santos VM, Müller M, de Vos WM. 2010. Systems biology of the gut: the interplay of food, microbiota and host at the mucosal interface. Curr Opinion Biotechnol 21:539550.

Dragoni I, Balzaretti C, Rossini S, Rossi L, Dell'Orto V, Baldi A. 2010. Detection of hen lysozyme on proteic profiles of grana padano cheese through SELDI-TOF MS high-throughput technology during the ripening process. Food Anal Methods In press. (DOI: $10.1007 / \mathrm{s} 12161-010-9146-4)$ 
Economou A., Botisi H., Antoniou S, Tsipi D. 2009. Determination of multi-class pesticides in wines by solid-phase extraction and liquid chromatography-tandem mass spectrometry. J Chromatogr A 1212:5856-5867.

EFSA. 2006. Guidance document of the scientific panel on genetically modified organisms for the risk assessment of genetically modified plants and derived food and feed. EFSA Communications Departmente, Parma, Italy.

EFSA. 2010. Opinions of the NDA panel published on 2009 and 2010. http://www.efsa.europa.eu/cs/Satellite (accessed on April 7, 2010).

Ercolini D, Russo F, Nasi Am Ferranti P, Villani F. 2009. Mesophilic and psychrotrophic bacteria from meat and their spoilage potential in vitro and in beef. Appl Environ Microbiol 75:1990-2001.

Erny GL, León C, Marina ML, Cifuentes A. 2008. Time of flight versus ion trap MS coupled to CE to analyse intact proteins. J Sep Sci 31:1810-1818.

Fardet A, Canlet C, Gottardi G, Lyan B, Llorach R, Rémésy C, Mazur A, Paris A, Scalbert A. 2007. Whole-grain and refined wheat flours show distinct metabolic profiles in rats as assessed by a H-1 NMR-based metabonomic approach. J Nutr 137:923-929.

Feng X, Liu X, Luo Q, Liu BF. 2008. Mass spectrometry in systems biology: An overview. Mass Spectrom Rev 27:635-660.

Fernandez C, Astier C, Rock E, Coulon JB, Berdague JL. 2003. Characterization of milk by analysis of its terpene fractions. Int J Food Sci Technol 38:445-451.

Fernandez-Moreno JL., Garrido Frenich A, Plaza Bolaños P, Martinez Vidal JL. 2008. Multiresidue method for the analysis of more than 140 pesticide residues in fruits and vegetables by gas chromatography coupled to triple quadrupole mass spectrometry. $\mathbf{J}$ Mass Spectrom 43:1235-1254. 
Ferrer I, Thurman EM. 2007. Multi-residue method for the analysis of 101 pesticides and their degradates in food and water samples by liquid chromatography/time-of-flight mass spectrometry. J Chromatogr A 1175:24-37.

Fogle RL, Lynch CJ, Palopoli M, Deiter G, Stanley BA, Vary TC. 2010. Impact of chronic alcohol ingestion on cardiac muscle protein expression. Alcohol Clin Exp Res $34: 1226-1234$.

Fulcrand H, Mane C, Preys S, Mazerolles G, Bouchut C, Mazaurinc JP, Souquet JM, Meudec E, Li Y, Cole RB, Cheynier V. 2008. Direct mass spectrometry approaches to characterize polyphenol composition of complex samples. Phytochemistry 69:31313138.

Fuchs B, Schiller J. 2009. Application of MALDI-TOF mass spectrometry in lipidomics. Eur J Lipid Sci Technol. 111:83-98.

Gagriaire V, Jardin J, Jan G, Lortal S. 2009. Invited review: proteomics of milk and bacteria ised in fermented dairy products: from qualitative to quantitative advances. $\mathbf{J}$ Dairy Sci. 92:811-825.

Garcia DE, Baidoo EE, Benke PI, Pingitore F, Tang YJ, Villa S, Keasling JD. 2008. Separation and mass spectrometry in microbial metabolomics. Curr Opinion Microbiol 11:233-239.

Garcia-Cañas V, Simó C, Leon C, Cifuentes A. 2010. Advances in Nutrigenomics research: Novel and future analytical approaches to investigate the biological activity of natural compounds and food functions. J Pharm Biomed Anal 51:290-304.

García-Cañas V, Simó C, León C, Ibáñez E, Cifuentes A. In press. MS-based analytical methodologies to characterize genetically modified crops. Mass Spec Rev.

García-López MC, Garcia-Cañas V, Marina ML. 2009. Reversed-phase highperformance liquid chromatography-electrospray mass spectrometry profiling of 
transgenic and non-transgenic maize for cultivar characterization. J Chromatogr A 1216:7222-7228.

Garcia-Villalba R, León C, Dinelli G, Segura-Carretero A, Fernandez-Gutierrez A, Garcia-Cañas V, Cifuentes A. 2008. Comparative metabolomic study of transgenic versus conventional soybean using capillary electrophoresis-time-of-flight mass spectrometry. J Chromatogr A 1195:164-173.

García-Villalba R, León C, Dinelli G, Segura-Carretero A, Fernández-Gutiérrez A, Garcia-Cañas V, Cifuentes A. 2008. Transgenic vs. conventional soybean: a comparative metabolomic study using capillary electrophoresis-time of flight-mass spectrometry. J Chromatogr A 1195:164-73.

Gaugain-Juhel M, Delépine B, Gautier S, Fourmond MP, Gaudin V, Hurtaud-Pessel D, Verdon E, Sanders P. 2009. Validation of a liquid chromatography-tandem mass spectrometry screening method to monitor 58 antibiotics in milk: a qualitative approach. Food Addit Contam 26:1459-1471.

Gehlenborg N, O'Donoghue SI, Baliga NS, Goesmann A, Hibbs MA, Kitano H, Kohlbacher O, Neuweger H, Schneider R, Tenenbaum D, Gavin AC. 2010. Visualization of omics data for systems biology. Nat Methods 7:S56-68.

Gilad O, Jacobsen S, Stuer-Lauridsen B, Pedersen, MB, Garrigues C, Svensson B. 2010. Combined transcriptome and proteome analysis of Bifidobacterium animalis subsp. lactis BB-12 grown on xylo-oligosaccharides and a model of their utilization. Appl Env Microb 76:7285-7291.

Gilbert-Lopez B, Garcia-Reyes JF, Mezcua M, Ramos-Martos N, Fernendez-Alba AR, Molina-Diaz A. 2010. Multi-residue determination of pesticides in frui-based soft drinks by fast liquid chromatography time-of-flight mass spectrometry. Talanta 81:1310-1321. 
Giuffrida A, León C, García-Cañas V, Cucinotta V, Cifuentes A. 2009. Modified cyclodextrins for fast and sensitive chiral-capillary electrophoresis-mass spectrometry. Electrophoresis 30:1734-1742.

Gomez-Ariza JL, Arias-Borrego A, Garcia-Barrera. 2006. Use of low injection atmospheric pressure photoionization quadrupole time-of-flight mass spectrometry for fast olive oil fingerprinting. Rapid Commun Mass Spectrom 20:1181-1186.

Gomez-Ruiz JA, Taborda G, Amigo L, Recio I, Ramos M. 2006. Identification of ACEinhibitory peptides in different Spanish cheeses by tandem mass spectrometry. Eur Food Res Technol. 223:595-601.

Gottlieb DM, Schultz J, Petersen M, Nesic L, Jacobsen S, Sondergaard I. 2002. Determination of wheat quality by mass spectrometry and multivariate data analysis. Rapid Commun Mass Spectrom 16:2034-2039.

Griffiths HR, Grant MM. 2006. The use of proteomic techniques to explore the holistic effects of nutrients in vivo. Nutr Res Rev 19:284-293.

Griffiths WJ, Wang YQ. 2009. Mass spectrometry: from proteomics to metabolomics and lipidomics. Chem Soc Rev 38:1882-1896.

Grün CH, van Dorsten FA, Jacobs DM, Le Belleguic M, van Velzen EJ, Bingham MO, Janssen HG, van Duynhoven JP. 2008. GC-MS methods for metabolic profiling of microbial fermentation products of dietary polyphenols in human and in vitro intervention studies. J Chromatogr B 871:212-219.

Han X, Aslanian A, Yates JR. 2008. Mass spectrometry for proteomics. Curr Opinion Chem. Biol. 12:483-490.

Herrero M, García-Cañas V, Simo C, Cifuentes A. 2010. Recent advances in the application of CE methods for food analysis and foodomics. Electrophoresis 31:205228. 
Herrero M, Ibañez E, Cifuentes A. 2008. Capillary electrophoresis-electrospray-mass spectrometry in peptide analysis and peptidomics. Electrophoresis 29:2148-2160.

Hirai MY, Yano M, Goodenowe DB, Kanaya S, Kimura T, Awazuhara M, Arita M, Fujiwara T, Saito K. 2004. Integration of transcriptomics and metabolomics for understanding of global responses to nutritional stress in Arabidopsis thaliana. PNAS 101:10205-10210.

Hood L, Health JR, Phelps MR, Lin B. 2004. Systems biology and new technologies enable predictive and preventative medicine. Science 306:640-643.

Hsieh LS, Moharram R, Akasawa A, Slater J, Martin BM. 2002. Banana allergen detection and identification using SELDI technology. J Allergy Clin Immunol 1:S305.

Hu A, Chen CT, Tsai PJ, Ho YP. 2006. Using capillary electrophoresis-selective tandem mass spectrometry to identify pathogens in clinical samples. Anal Chem 78:5124-5133.

Huang JT, Leweke FM, Tsang TM, Koethe D, Kranaster L, Gerth CW, Gross S, Schreiber D, Ruhrmann S, Schultze-Lutter F, Klosterkötter J, Holmes E, Bahn S. 2007. CSF metabolic and proteomic profiles in patients prodromal for psychosis. Plos ONE 2: e756.

Huang Z, Li Y, Chen B, Yao S. 2007. Simultaneous determination of 102 pesticide residues in Chinese teas by gas chromatography-mass spectrometry. J Chromatogr B $856: 154-162$.

Ioset JR, Urbaniak B, Ndjoko-Ioset K, Wirth J, Martin F, Gruissem W, Hostettmann K, Sautter C. 2007. Flavonoid profiling among wild type and related GM wheat varieties. Plant Mol Biol 65:645-654. 
Islam N, Campbell PM, Higgins TJV, Hirano H, Akhurst RJ. 2009. Transgenic peas expressing an $\alpha$-amylase inhibitor gene from beans show altered expression and modification of endogenous proteins. Electrophoresis 30:1863-1868.

Issaq HJ, Van QN, Waybright TJ, Muschik GM, Veenstra TD. 2009. Analytical and statistical approaches to metabolomics research. J Sep Sci 32:2183-2199.

Jimenez JJ, Bernal JL, Nozal MJ, Toribio L, Bernal J. 2009. Profile and relative concentrations of fatty acids in corn and soybean seeds from transgenic and isogenic crops. J Chromatogr A 1216:7288-7295.

Joo JI, Kim DH, Choi JW, Yun JW. 2010. Proteomic analysis for antiobesity potential of capsaicin on white adipose tissue in rats fed with a high fat diet. J Proteome Res 9:2977-2987.

Kankar B, Mandal S, Bhattacharyya. 2010. Validation and uncertainty analysis of a multiresidue method for 42 pesticides in made tea, tea infusion and spent leaves using ethyl acetate extraction and liquid chromatography-tandem mass spectrometry. J Chromatogr A 1217:1926-1933.

Kim DH, Joo JI, Choi JW, Yun JW. 2010. Differential expression of skeletal muscle proteins in high-fat diet-fed rats in response to capsaicin feeding. Proteomics 10:28702881.

Kinsella B, Lehotay SJ, Mastovska K, Lightfield AR, Furey A, Danaher M. 2009. New method for the analysis of flukicide and other anthelmintic residues in bovine milk and liver using liquid chromatography-tandem mass spectrometry. Anal Chim Acta 637:196-207.

Klaus K. Unger, R. Ditz, E. Machtejevas, R. Skudas. 2010. Liquid chromatography-Its development and key role in life science applications. Angew. Chem. Int. Ed. 49:23002312. 
Kohanski MA, Dwyer DJ, Wierzbowski J, Cottarel G, Collins JJ. 2008. Mistranslation of membrane proteins and two-component system activation trigger antibiotic-mediated cell death. Cell 135:679-690.

Krishnan HB, Kim WS, Jang S. Kerley MS. 2009. All three subunits of soybean $\beta$ conglycinin are potential food allergens. J Agric Food Chem 57:938-943.

Kwon SW. 2004. Profiling of soluble proteins in wine by nano-high performance liquid chromatography/tandem mass spectrometry. J Agric Food Chem 52:7258-7263.

Lehesranta SJ, Davies HV, Shepherd LV, Nunan N, McNicol JW, Auriola S, Koistinen KM, Suomalainen S, Kokko HI, Kärenlampi SO. 2005. Comparison of tuber proteomes of potato varieties, landraces, and genetically modified lines. Plant Physiol 138:16901699.

León C, Rodriguez-Meizoso I, Lucio M, Garcia-Cañas V, Ibañez E, Schmitt-Kopplin P, Cifuentes A. 2009. Metabolomics of transgenic foods combining Fourier Transform-Ion Cyclotron Resonance-Mass Spectrometry, capillary electrophoresis-mass spectrometry and pressurized liquid extraction. J Chromatogr A 1216:7314-7323.

Lerma-Garcia MJ, Herrero-Martinez JM, Ramis-Ramos G, Simo-Alfonso, EF. 2008. Prediction of the genetic variety of Spanish extra virgin olive oils using fatty acid and phenolic compound profiles established by direct infusion mass spectrometry. Food Chem 108:1142-1148.

Levandi T, Leon C, Kaljurand M, Garcia-Cañas V, Cifuentes A. 2008. Capillary electrophoresis-time of flight-mass spectrometry for comparative metabolomics of transgenic vs. conventional maize. Anal Chem 80:6329-6335.

Li F, Zhao Q, Wang C, Lu X, Li XF, Le C. 2010. Detection of Escherichia coli O157:H7 using gold nanoparticle labelling and inductively coupled plasma mass spectrometry. Anal Chem 82:3399-3403. 
Llorach-Asunción R, Jauregui O, Urpi-Sarda M, Andres-Lacueva C. 2010. Methodological aspects for metabolome visualization and characterization. A metabolomic evaluation of the $24 \mathrm{~h}$ evolution of human urine after cocoa powder consumption. J Pharm Biomed Anal 51:373-381.

Lo Feudo G, Naccarato A, Sindona G, Tagarelli A. 2010. Investigating the origin of tomatoes and triple concentrated tomato pastes through multielement determination by inductively coupled plasma mass spectrometry and statistical analysis. J Agric Food Chem 58:3801-3807.

Mahn AV, Toledo HM, Ruz M. 2009. Dietary supplementation with selenomethylselenocysteine produces a differential proteomic response. J Nutr Biochem 20:791-799.

Malik AK, Blasco C, Pico Y. 2010. Liquid chromatography-mass spectrometry in food safety. J Chromatogr A. 1217:4018-4040.

Malowicki SMM, Martin R, Qian MC. 2008. Comparison of sugar, acids, and volatile composition in raspberry bushy dwarf virus-resistant transgenic raspberries and the wild type 'Meeker' (Rubus Idaeus L.). J Agric Food Chem 56:6648-6655.

Mannas D, Altug T. 2007. SPME/GC/MS and sensory flavour profile analysis for estimation of authenticity of thyme honey. Int J Food Sci Technol 42:133-138.

Matsuda F, Ishihara A, Takanashi K, Morino K, Miyazawa H, Wakasa K, Miyagawa H. 2010. Metabolic profiling analysis of genetically modified rice seedlings that overproduce tryptophan reveals the occurrence of its inter-tissue translocation. Plant Biotechnol 27:17-27.

Mattivi F, Guzzon R, Vrhovsek U, Stefanini M, Velasco R. 2006. Metabolite profiling of grape: flavonols and anthocyanins. J Agric Food Chem 54:7692-7702. 
Mazzeo MF, de Giulio B, Guerriero G, Ciarcia G, Malorni A, Russo GL, Siciliano RA. 2010. Fish authentication by MALDI-TOF mass spectrometry. J Agric Food Chem $56: 11071-11076$.

Moco S, Bino RJ, Vorst O, Verhoeven HA, de Groot J, van Beek TA, Vervoort J, de Vos CHR. 2006. A liquid chromatography-mass spectrometry-based metabolome database for tomato. Plant Physiol 141:1205-1218.

Motoyama A, Yates JR. 2008. Multidimensional LC separations in Shotgun Proteomics. Anal Chem 80:7187-7193.

Mungur R, Glass AND, Goodenow DB, Lightfoot DA. 2005. Metabolite fingerprinting in transgenic Nicotiana tabacum altered by the Escherichia coli glutamate dehydrogenase gene. J BioMed Biotechnol 2:198-214.

Nagai YS, Sakulsinghroj C, Edwards GE, Satoh H, Greene TW, Blakeslee B, Okita TW. 2009. Control of Starch Synthesis in Cereals: Metabolite Analysis of Transgenic Rice Expressing an Up-Regulated Cytoplasmic ADP-Glucose Pyrophosphorylase in Developing Seeds. Plant Cell Physiol 50:635-643.

Narasaka S, Endo Y, Fu Z, Moriyama M, Arai S, Abe K, Kato H. 2006. Safety evaluation of hypoallergenic wheat flour by using a DNA microarray. Biosci Biotechnol Biochem 70:1464-1470.

Natale M, Bisson C, Monti G, Peltran A, Garoffo LP, Valentini S, Fabris C, Bertino E, Coscia A, Conti A. 2004. Cow's milk allergens identification by two dimensional immunoblotting and mass spectrometry. Mol Nutr Food Res 48:363-369.

Nicoletti I, De Rossi A, Giovinazzo G, Corradini D. 2007. Identification and quantification of stilbenes in fruits of transgenic tomato plants (Lycopersicon esculentum Mill.) by reversed phase HPLC with photodiode array and mass spectrometry detection. J Agric Food Chem 55:3304- $\square 3311$. 
Ninonuevo MR, Park Y, Yin H, Zhang J, Ward RE, Clowers BH, German JB, Freeman SL, Killeen K, Grimm R, Lebrilla CB. 2006. A strategy for annotating the milk glycome. J Agric Food Chem 54:7471-7480.

Novak EM, Lee EK, Innis SM, Keller BO. 2009. Identification of novel protein targets regulated by maternal dietary fatty acid composition in neonatal rat liver. $\mathrm{J}$ Proteom 73 : 41-49.

Oh E, Hasan MN, Jamshed M, Park SH, Hong HM, Song EJ, Yoo YS. 2010. Growing trend of $\mathrm{CE}$ at the omics level: The frontier of systems biology. Electrophoresis 31:7492.

Organization of Economic Cooperation \& Development (OECD). 1993. Safety Evaluation of Foods Derived by Modern Biotechnology: Concepts and Principles, Organisation for Economic Co-operation and Development, Paris, (http://www.oecd.org/pdf/M00034000/M00034525.pdf).

Ortea I, Cañas B, Gallardo JM. 2009. Mass spectrometry characterization of speciesspecific peptides from arginine kinase for the identification of commercially relevant shrimp species. J Proteome Res 8:5356-5362.

Pakalapati G, Li N, Gretz N, Koch E, Wink M. 2009. Influence of red clover (Trifolium pratense) isoflavones on gene and protein expression profiles in liver of ovariectomize drats. Phytomedicine 16:845-855.

Panagiotou G, Nielsen J. 2009. Nutritional systems biology: definitions and approaches. Ann Rev Nutr 29:329-39.

Pasikanti KK, Ho PC, Chan EC. 2008. Gas chromatography/mass spectrometry in metabolic profiling of biological fluids. J Chromatogr B 871:202-211. 
Petit L, Pagny G, Baraige F, Nignol AC, Zhang D. 2007. Characterization of genetically modified maize in weakly contaminated seed batches and identification of the origin of the adventitious contamination. J AOAC Int 90:1098-1106.

Powell K. 2007. Functional foods from biotech-an unappetizing prospect? Nature 25:525-531.

Ramautar R, Somsen GW, de Jong GJ. 2009. CE-MS in metabolomics. Electrophoresis 30:276-291.

Raqib R, Cravioto A. 2009. Nutrition, immunology, and genetics: future perspectives. Nutr Rev 67:S227-236.

Rasmussen RR, Stom IMLD Rasmussen PH, Smedsgaard J, Nielsen KF. 2010. Multimycotoxin analysis of maize silage by LC-MS/MS. Anal Bioanal Chem 397:765-776.

Ren Y, Lv J, Wang H, Li L, Peng Y, Qu LJ. 2009. A comparative proteomics approach to detect unintended effects in transgenic Arabidopsis. J Genet Genomics 36:629-239.

Rezzi S, Ramadan Z, Fay LB, Kochhar S. 2007. Nutritional metabonomics: applications and perspectives. J Proteome Res 6:513-525.

Rist MJ, Wenzel U, Daniel H. 2006. Nutrition and food science go genomic. Trends Biotechnol 24:1-7.

Risticevic S, Carasek E, Pawliszyn J. 2008. Headspace solid-phase microextraction-gas chromatography-time-of-flight mass spectrometric methodology for geographical origin verification of coffee. Anal Chim Acta 617:72-84.

Ritz MF, Ratajczak P, Curin Y, Cam E, Mendelowitsch A, Pinet F, Andriantsitohaina R. 2008. Chronic treatment with red wine polyphenol compounds mediates neuroprotection in a rat model of ischemic cerebral stroke. J Nutr 138:519-525.

Rocha SM, Coehlo E, Zrostlikova J, Delgadillo I, Coimbra MA. 2007. Comprehensive two-dimensional gas chromatography with time-of-flight mass spectrometry of 
monoterpenoids as a powerful tool for grape origin traceability. J Chromatogr A 1161:292-299.

Roessner U, Luedemann A, Brust D, Fiehn O, Linke T, Willmitzer L, Fernie AR. 2001. Metabolic profiling allows comprehensive phenotyping of genetically or environmentally modified plant systems. Plant Cell 13:11-29.

Roessner U, Wagner C, Kopka J, Trethewney RN, Willmitzer L. 2000. Simultaneous analysis of metabolites in potato tuber by gas chromatography-mass spectrometry. Plant J 23:131-142.

Roessner U, Willmitzer L, Fernie AR. 2001. High-resolution metabolic phenotyping of genetically and environmentally diverse potato tuber systems. Identification of phenocopies. Plant Physiol 127:749-764.

Roessner-Tunali U, Hegemann B, Lytovchenko A, Carrari F, Bruedigam C, Granot D, Fernie AR. 2003. Metabolic profiling of transgenic tomato plants overexpressing hexokinase reveals that the influence of hexose phosphorylation diminishes during fruit development. Plant Physiol 133:84-99.

Ronteltap A, van Trijp JCM, Renes RJ. 2007. Expert views on critical success and failure factors for Nutrigenomics. Trends Food Sci. Tech. 18:189-200.

Rowell C, Carpenter DM, Lamartiniere CA. 2005. Chemoprevention of breast cancer, proteomic discovery of genistein action in the rat mammary gland. J Nutr 135:2953S2959S.

Ruebelt MC, Leimgruber NK, Lipp M, Reynolds TL, Nemeth MA, Astwood JD, Engel KH, Jany KD. 2006a. Application of two-dimensional gel electrophoresis to interrogate alterations in the proteome of genetically modified crops. 1. Assessing analytical validation. J Agric Food Chem 54:2154-2161. 
Ruebelt MC, Lipp M, Reynolds TL, Astwood JD, Engel KH, Jany KD. 2006b. Application of two-dimensional gel electrophoresis to interrogate alterations in the proteome of genetically modified crops. 2. Assessing natural variability. J Agric Food Chem 54:2162-2168.

Ruebelt MC, Lipp M, Reynolds TL, Schmuke JJ, Astwood JD, DellaPenna D, Engel KH, Jany KD. 2006c. Application of two-dimensional gel electrophoresis to interrogate alterations in the proteome of genetically modified crops. 3. Assessing unintended effects. J Agric Food Chem 54:2169-2177.

Rudell DR, Mettheis JP, Curry EA. 2008. Prestorage ultraviolet-white light irradiation alters apple peel metabolome. J Agric Food Chem 56:1138-1147.

Saito K, Matsuda F. 2010. Metabolomics for funcional genomics, systems biology and biotechnology. Annu Rev Plant Biol 61:463-489.

Sandra K, Moshir M, D'hondt F, Tuytten R, Verleysen K, Kas K, Francois I, Sandra P. 2009. Highly efficient peptide separations in proteomics Part 2: $\mathrm{Bi}^{-}$and multidimensional liquid-based separation techniques. J Chromatogr B 877:1019-1039.

Schiplilliti L, Tranchida P, Sciarrone D, Russo M, Dugo P, Dugo G, Mondello L. 2010. Genuineness assessment of mandarin essential oils employing gas chromatographycombustion-isotope ratio MS (GC-C-IRMS). J Sep Sci 33:617-625.

Schittmayer M, Birner-Gruenberger R. 2009. Functional proteomics in lipid research: Lipases, lipid droplets and lipoproteins, J Proteom 72:1006-1018.

Schnackenberg LK, Jones RC, Thyparambil S, Taylor JT, Han T, Tong W, Hansen DK, Fuscoe JC, Edmondson RD, Beger RD, Dragan YP. 2006. An integrated study of acute effects of valproic acid in the liver using metabonomics, proteomics, and transcriptomics platforms. OMICS 10:1-14. 
Scossa F, Laudencia-Chingcuanco D, Anderson OD, Vensel WH, Lafiandra D, D'Ovidio R, Masci S. 2008. Comparative proteomic and transcriptional profiling of a bread wheat cultivar and its derived transgenic line overexpressing a low molecular weight glutenin subunit gene in the endosperm. Proteomics 8:2948-2966.

Shin YM, Park HJ, Yim SD, Baek NI, Lee CH, An G, Woo YM. 2006. Transgenic rice lines expressing maize $\mathrm{C} 1$ and $\mathrm{R}-\mathrm{S}$ regulatory genes produce various flavonoids in the endosperm. Plant Biol J 4:303-315.

Shu XL, Frank T, Shu QY, Engel KH. 2008. Metabolite profiling of germinating rice seeds. J Agric Food Chem. 56:11612-11620.

Shulaev V. 2006. Metabolomics technology and bioinformatics. Briefings in Bioinformatics. 7:128-139.

Simó C, Domínguez-Vega E, Marina ML, García MC, Dinelli G, Cifuentes A. 2010. CE-TOF MS analysis of complex protein hydrolyzates from genetically modified soybeans-A tool for foodomics. Electrophoresis 31:1175-1183.

Smolenski G, Haines S, Kwan FYS, Bond J, Farr V, Davis SR, Stelwagen K, Wheeler TT. 2007. Characterization of host defense proteins in milk using a proteomic approach. J Proteome Res 6:207-215.

Starling, S. 2010. EFSA mass rejects probiotics and antioxidants as article 13.1 batch two published. http://www.beveragedaily.com/Product-Categories/Ingredients-andadditives/EFSA-mass-rejects-probiotics-and-antioxidants-as-article-13.1-batch-twopublished (accessed on April 7, 2010).

Subbiah MTR. 2006. Nutrigenetics and nutraceuticals: the next wave riding on personalized medicine. Translational Res 149:55-61.

Suhre K, Schmitt-Kopplin P. 2008. MassTRIX: mass translator into pathways. Nucleic Acids Res. 36:W481-484. 
Szopinska A, Morsomme P. 2010. Quantitative proteomic approaches and their application in the study of yeast stress responses. Omics J Int Biol 14:639-649.

Takahashi H, Hayashi M, Goto F, Sato S, Soga T, Nishioka T, Tomita M, KawaiYamada M, Uchimiya H. 2006. Evaluation of Metabolic Alteration in Transgenic Rice Overexpressing Dihydroflavonol-4-reductase. Ann Bot 98:819-825.

Takahashi H, Hotta Y, Hayashi M, Kawai-Yamada M, Komatsu S, Uchimiya H. 2005. High throughput metabolome and proteome analysis of transgenic rice plants (Oryza sativa L.). Plant Biotech 22:47-50.

Taylor MJ, Keenan GA, Reid KB, Fernandez DU. 2008. The utility of ultraperformance liquid chromatography/electrospray ionisation time-of-flight mass spectrometry for multi-residue determination of pesticides in strawberry. Rapid Commun Mass Spectrom 22:2731-2746.

Tesniere C, Torregrosa L, Pradal M, Souquet JM, Gilles C, Dos Santos K, Chatelet P, Gunata Z. 2006. Effects of genetic manipulation of alcohol dehydrogenase levels on the response to stress and the synthesis of secondary metabolites in grapevine leaves. J Exp Bot 57:91-99.

Timms JF, Cramer R. 2008. Difference gel electrophoresis. Proteomics 8:4886-4897.

Trujillo E, Davis C, Milner J. 2006. Nutrigenomics, proteomics, metabolomics and the practice of diets. J Am Diet Assoc 106:403-414.

Vaclavik L, Cajka T, Hrbek V, Hajslova J. 2009. Ambient mass spectrometry employing direct analysis in real time (DART) ion source for olive oil quality and authenticity assessment. Anal Chim Acta 645:56-63.

Van der Lee MK, van der Weg G, Traag WA, Mol HGJ. 2008. Qualitative screening and quantitative determination of pesticides and contaminants in animal feed using 
comprehensive two-dimensional gas chromatography with time-of-flight mass spectrometry. J Chromatogr A 1186:325-339.

Waagmeester AS, Kelder T, Evelo CTA. 2008. The role of bioinformatics in pathway curation. Genes Nutr 3:139-142.

Walorczyk S. 2008. Development of a multi-residue method for the determination of pesticides in cereals and dry animal feed using gas chromatography-tandem quadrupole mass spectrometry II. Improvement and extension to new analytes. J Chromatogr A 1208:202-214.

Wang J, Kliks MM, Qu W, Jun S, Shi G, Li QX. 2009a. Rapid determination of the geographical origin of honey based on protein fingerprinting and barcoding using MALDI TOF MS. J Agric Food Chem 57:10081-10088.

Wang J, Leung D, Chow W. 2010. Applications of LC/ESI-MS/MS and UHPLC QqTOF MS for te determination of 148 pesticides in berries. J Agric Food Chem 58:5904-5925.

Wang X, Ou D, Yin J, Wu G, Wang J. 2009b. Proteomic analysis reveals altered expression of proteins related to glutathione metabolism and apoptosis in the small intestine of zinc oxide-supplemented piglets. Amino Acids 37:209-218.

Weston AD, Hood L. 2004. Systems Biology, Proteomics, and the Future of Health Care: Toward Predictive, Preventative, and Personalized Medicine. J Proteome Res 3:179-196.

Wong J, Hao C, Zhang K, Yang P, Banerjee K, Hayward D, Iftakhar I, Schreiber A, Tech K, Sack C, Smoker M, Chen X, Utture SC, Oulkar DP. 2010a. Development and Interlaboratory Validation of a QuEChERS-Based Liquid Chromatography-Tandem Mass Spectrometry Method for multiresidue Pesticide Analysis. J Agric Food Chem 58:5897-5903. 
Wong JW, Zhang K, Tech K, Hayward DG, Makovi CM, Krynitsky AJ, Schenck FJ, Banerjee K, Dasgupta S, Brown D. 2010b. Multiresidue pesticide analysis in fresh produce by capillary gas chromatography-mass spectrometry/selective ion monitoring (GC-MS/SIM) and -tandem mass spectrometry (GC-MS/MS). J Agric Food Chem 58:5868-5883.

Xiayan L, Legido-Quigley C. 2008. Advances in separation science applied to metabonomics. Electrophoresis 29:3724-3736.

Xu XL, Li L, Zhong WK, He YJ. 2009. Multi-Residue Analysis of 205 Crop Pesticides Using Mini-Solid Phase Extraction-Large Volume Injection-GC-MS. Chromatographia 70:173-183.

Xu Y, Cheung W, Winder CL, Gooacre R. 2010. VOC-based metabolic profiling for food spoilage detection with the application to detecting Salmonella typhimuriumcontaminated pork. Anal Bioanal Chem 397:2439-2449.

Xu Y, Heilier JF, Madalinski G, Genin E, Ezan E, Tabet JC, Junot C. 2010. Evaluation of accurate mass and relative isotopic abundance measurements in the LTQ-Orbitrap mass spectrometer for further metabolomics database building. Anal Chem 82:54905501.

Yates JR, Ruse CI, Nakorchevsky A. 2009. Proteomics by mass spectrometry: Approaches, advances, and applications. Annual Rev Biomed Eng 11:49-79.

Zachariasova M, Lacina O, Malachova A, Kostelanska M, Poutska J, Godula M, Hajslova J. 2010. Novel approaches in analysis of Fusarium mycotoxins in cereals employing ultra performance liquid chromatography coupled with high resolution mass spectrometry. Anal Chim Acta 662:51-61. 
Zawirska-Wojtasiak R, Gonslinski M, Szwacka, Gajc-Wolska J, Mildner-Szkudlarz S. 2009. Aroma Evaluation of Transgenic, Thaumatin II-Producing Cucumber Fruits. J Food Sci 74:204-210.

Zhan D, Desiderio, D. 2003 Differences in the spatial and quantitative reproducibility between two second-dimensional gel electrophoresis systems. Electrophoresis 24:18341846.

Zhou J, Ma C, Xu H, Yuan K, Lu X, Zhu Z, Wu Y, Xu G. 2009. Metabolic profiling of transgenic rice with cryIAc and sck genes: An evaluation of unintended effects at metabolic level by using GC-FID and GC-MS. J Chromatogr B 877:725-732.

Zolla L, Rinalducci S, Antonioli P, Righetti PG. 2008. Proteomics as a complementary tool for identifying unintended side effects occurring in transgenic maize seeds as a result of genetic modifications. J Proteome Res 7:1850-1861.

Zorb C, Betsche T, Langenkamper G. 2009. Search for diagnostic proteins to prove authenticity of organix wheat grains (Triticum aestivum L). J Agric Food Chem. 57:2932-2937.

Zorb C, Langenkamper G, Betsche T, Niehaus K, Barsch A. 2006. Metabolite profiling of wheat grains (Triticum aestivum L.) from organic and conventional agriculture. $\mathbf{J}$ Agric Food Chem 54:8301-8306. 


\section{FIGURE LEGENDS}

Figure 1. Foodomics: covered areas, tools, and goals.

Figure 2. Scheme of the different strategies that can be followed to carry out a proteomic study.

Figure 3. Three-dimensional and contour plot obtained after the analysis with GCxGCTOF-MS of a standard solution that contains 360 pesticides (reproduced from Van der Lee et al., 2008).

Figure 4. MALDI-TOF-MS spectral profiles of Enterobacter spp., R. planticola, Klebsella spp., and Providencia spp with species-specific peaks indicated with an asterisk, genus-specific peaks with a circle, and further characteristic peaks with a triangle (reproduced from Bohme et al., 2010).

Figure 5. Transformation process of protein ion-mass spectral barcodes from a MALDI-TOF-MS spectrum of proteins extracted from a honey sample (left): A) MALDI-TOF-MS raw mass spectrum, B) graphic output of the identification results displayed within the graphic view, C) the peaks transformed into barcodes; and MALDI-TOF protein mass spectral barcodes and selected enlargements (right) of 16 different honeys of known origin (reproduced from Wang et al., 2009a).

Figure 6. CE-TOF-MS base-peak electrophoregram of the digested protein extract from conventional and transgenic soybean (Redrawn from Simó et al., 2010).

Figure 7. Profile of phenolic acids in urine after intake of grape juice/wine extract. (A) GC-MS profiles of ethyl acetate extracts of human urine of placebo (top chromatogram) and intervention (bottom chromatogram). (B) OPLS analysis of the GC-MS profiles of urine to show the different metabolic impact of intervention vs. placebo intake. (C) OPLS coefficients plots to indicate the metabolites that increased after intervention (Redrawn from Grün et al., 2008). 
Table 1. Some representative Foodomics applications for the simultaneous analysis with MS-based methodologies of more than 30 pesticides and/or antimicrobials in foods.

\begin{tabular}{|c|c|c|c|c|c|}
\hline \multirow{2}{*}{ Compounds determined } & \multirow{2}{*}{ Food } & \multirow{2}{*}{ MS based tool } & \multicolumn{2}{|c|}{ Sensitivity } & \multirow{2}{*}{ Ref. } \\
\hline & & & LOD & LOQ & \\
\hline $\begin{array}{c}31 \text { antimicrobials (including } \beta \text {-lactams, lincosamides, } \\
\text { macrolides, quinolones, sulfonamides, tetracyclines, } \\
\text { nitroimidazoles and trimethoprim) }\end{array}$ & Meat (bovine and pork) & $\begin{array}{l}\text { LC-ESI-MS/MS (QqQ in } \\
\text { SRM mode) }\end{array}$ & $3-10 \mu \mathrm{g} \mathrm{kg}^{-1}$ & $15-50 \mu \mathrm{g} \mathrm{kg}^{-1}$ & $\begin{array}{c}\text { Carretero, } \\
\text { Blasco \& Pico, } \\
2008\end{array}$ \\
\hline 44 pesticides & Raw bovine milk & $\begin{array}{l}\text { LC-ESI-MS/MS (QqQ in } \\
\text { SRM mode) }\end{array}$ & $0.05-3 \mathrm{ng} \mathrm{g}^{-1}$ & $0.2-10.1 \mathrm{ng} \mathrm{g}^{-1}$ & $\begin{array}{l}\text { Dagnac et al., } \\
2009\end{array}$ \\
\hline $\begin{array}{l}\text { Antibiotics (penicillins, cephalosporins, sulfonamides, } \\
\text { macrolides, lincosamides, aminoglycosides, tetracyclines, } \\
\text { and quinolones) }\end{array}$ & Milk & $\begin{array}{l}\text { LC-ESI-MS/MS (QqQ in } \\
\text { MRM mode) }\end{array}$ & $4-100 \mu \mathrm{g} \mathrm{kg}^{-1}$ & & $\begin{array}{l}\text { Gaugain-Juhel } \\
\text { et al., } 2009\end{array}$ \\
\hline 106 pesticides and contaminants & Cereal products & GCxGC-TOF-MS & & $1-20 \mu \mathrm{g} \mathrm{kg}^{-1}$ & $\begin{array}{l}\text { Van der Lee et } \\
\text { al., } 2008\end{array}$ \\
\hline $\begin{array}{c}38 \text { anthelmintic (including benzimidazoles, macrocyclic } \\
\text { lactones, and flukicides) }\end{array}$ & Milk, liver & $\begin{array}{l}\text { LC-ESI-MS/MS (QqQ in } \\
\text { SRM mode) }\end{array}$ & & $5-10 \mu \mathrm{g} \mathrm{kg}^{-1}$ & $\begin{array}{l}\text { Kinsella et al., } \\
2009\end{array}$ \\
\hline $\begin{array}{c}47 \text { antibiotics (tetracyclines, quinolones, macrolides, } \\
\text { sulfonamides, diamino-pyrimidine derivatives and } \\
\text { lincosamides) }\end{array}$ & Milk & $\begin{array}{l}\text { LC-ESI-MS/MS (QqQ in } \\
\text { SRM mode) }\end{array}$ & $\begin{array}{c}{ }^{\mathrm{a}} 6.8-243 \mu \mathrm{g} \\
\mathrm{kg}^{-1}\end{array}$ & ${ }^{\mathrm{b}} 8.1-325 \mu \mathrm{g} \mathrm{kg}^{-}$ & $\begin{array}{l}\text { Bohm, Stachel } \\
\text { \& Gowik, } 2009\end{array}$ \\
\hline 148 pesticides & Berry fruits & $\begin{array}{l}\text { LC-ESI-MS/MS (QqQ in } \\
\text { MRM mode) }\end{array}$ & & $>5 \mu \mathrm{g} \mathrm{kg}^{-1}$ & $\begin{array}{l}\text { Wang, Leung } \\
\text { \& Chow, } 2010\end{array}$ \\
\hline 46 pesicides & Wines & $\begin{array}{l}\text { LC-ESI-MS/MS (QqQ in } \\
\text { SRM mode) }\end{array}$ & $0.3-3 \mu \mathrm{g} \mathrm{L} \mathrm{L}^{-1}$ & $1-10 \mu \mathrm{g} \mathrm{L}{ }^{-1}$ & $\begin{array}{l}\text { Economou et } \\
\text { al., } 2009\end{array}$ \\
\hline 191 pesticides & Fruits & $\begin{array}{l}\text { LC-ESI-MS/MS (QqQ in } \\
\text { MRM mode) }\end{array}$ & $0.5-5 \mathrm{ppb}$ & & $\begin{array}{l}\text { Wong et al., } \\
\text { 2010a }\end{array}$ \\
\hline 140 pesticides & Cereals & $\begin{array}{l}\text { GC-MS/MS (QqQ in MRM } \\
\text { mode) }\end{array}$ & & $0.01 \mathrm{mg} \mathrm{kg}^{-1}$ & $\begin{array}{l}\text { Walorczyk, } \\
2008\end{array}$ \\
\hline 205 pesticides & $\begin{array}{l}\text { Vegetables, fruits and } \\
\text { beans }\end{array}$ & LVI-GC-MS (SIM mode) & $\underset{\mathrm{kg}^{-1}}{0.15-200 \mu \mathrm{g}}$ & $0.5-600 \mu \mathrm{g} \mathrm{kg}^{-1}$ & Xu et al., 2009 \\
\hline $\begin{array}{c}130 \text { pesticides (including insecticides, herbicides, } \\
\text { fungicides and acaricides) }\end{array}$ & $\begin{array}{l}\text { Orange, nectarine and } \\
\text { spinach }\end{array}$ & $\begin{array}{l}\text { GC-MS/MS (QqQ in MRM } \\
\text { mode) }\end{array}$ & $0.1-50 \mu \mathrm{g} \mathrm{kg}^{-1}$ & $<0.01 \mathrm{mg} \mathrm{kg}^{-1}$ & $\begin{array}{l}\text { Cervera et al., } \\
\quad 2001\end{array}$ \\
\hline
\end{tabular}


33 multiclass pesticides

101 pesticides (including triazines, organophosphorous, carbamates, phenylureas, neonicotinoids)

$$
140 \text { pesticides }
$$

167 pesticides (organohalogen, organophosphorus ad pyrethroid)

102 pesticides

100 pesticides

42 pesticides

98 pesticides (organophosphorous and carbamates) and related products

82 pesticides
Fruit-based soft drinks

$$
\text { Vegetables }
$$

Cucumber and orange

Vegetables and fruits

Tea

Strawberry

Tea

edible oil, meat, egg,

cheese, chocolate,

coffee, rice, tree nuts,

citric fruits, vegetables

Pomegranate, apple,
UPLC-ESI-TOF-MS

LC-ESI-TOF-MS

GC-MS/MS (QqQ in MRM mode)

GC-MS/MS (QqQ in MRM mode)

GC-MS (SIM mode)

UPLC-TOF-MS

LC-MS/MS (QqQ in MRM mode)

LC-MS/MS (QqQ in MRM mode)

\begin{tabular}{|c|c|c|}
\hline & $0.02-2 \mu \mathrm{g} \mathrm{L}^{-1}$ & $\begin{array}{l}\text { Gilbert-Lopez } \\
\text { et al.. } 2010\end{array}$ \\
\hline \multirow{6}{*}{$\begin{array}{c}0.04-150 \\
\mathrm{~kg}^{-1}\end{array}$} & & Ferrer \& \\
\hline & & Thurman, 2007 \\
\hline & & Fernandez- \\
\hline & $10 \mu \mathrm{g} \mathrm{kg}^{-1}$ & $\begin{array}{c}\text { Morenoet al., } \\
2008\end{array}$ \\
\hline & $3.4 \mu \mathrm{g} \mathrm{kg}^{-1}$ & $\begin{array}{c}\text { Wong et al., } \\
2010\end{array}$ \\
\hline & $\underset{\mathrm{ml}^{-1}}{0.012-1.5 \mu \mathrm{g}}$ & $\begin{array}{c}\text { Huang et al., } \\
2007\end{array}$ \\
\hline \multirow[t]{7}{*}{$0.02 \mathrm{mg} \mathrm{kg}^{-1}$} & & Taylor et al., \\
\hline & & $\begin{array}{c}2008 \\
\text { Kankar. }\end{array}$ \\
\hline & $15 . \mathrm{log}^{-1}$ & Mandal \& \\
\hline & 4-4J $\mu \mathrm{g} \mathrm{kg}$ & $\begin{array}{c}\text { Bhattachatyya, } \\
2010\end{array}$ \\
\hline & $10 \mu \mathrm{g} \mathrm{k}^{-1}$ & Chung \& Chan, \\
\hline & $10 \mu \mathrm{g} \mathrm{kg}^{-1}$ & 2010 \\
\hline & $2.5-5.0 \mu \mathrm{g} \mathrm{kg}^{-1}$ & $\begin{array}{c}\text { Banerjee et al., } \\
2008\end{array}$ \\
\hline
\end{tabular}

LC-MS/MS (QqQ in MRM

${ }^{a} \mathrm{CC} \alpha$, decision limit; ${ }^{\mathrm{b}} \mathrm{CC} \beta$, detection capability 
Table 2. Some representative Foodomics applications in the field of Nutrigenomics that used MS-based proteomics.

\begin{tabular}{|c|c|c|c|c|}
\hline Bioactive compound (supplemented-diet) & Studied model & Issue & MS based tool & Ref. \\
\hline Vitamin E, selenium and lycopene & $\begin{array}{l}12 \mathrm{~T}-10 \text { transgenic mice } \\
\text { plasma }\end{array}$ & Prostate cancer & SDS/PAGE, LC-IT-MS & Cervi et al., 2010 \\
\hline $\begin{array}{l}\text { Genistein, biochanin A, formononetin, } \\
\text { glycetin (ISOFLAVONES) from red clover }\end{array}$ & Rat liver & Metabolism influence & 2-DE, MALDI-TOF-MS & $\begin{array}{l}\text { Pakalapati et al., } \\
2009\end{array}$ \\
\hline Red wine polyphenols & Rat brain & Cerebral stroke prevention & 2-DE, MALDI-TOF-MS & Ritz et al., 2008 \\
\hline Capsaicin & $\begin{array}{l}\text { Rat skeletal muscle cells } \\
\text { Rat white adipose tissue }\end{array}$ & Antiobesity effect & 2-DE, MALDI-TOF-MS & $\begin{array}{l}\text { Kim et al., 2010; } \\
\text { Joo et al., } 2010\end{array}$ \\
\hline Ethanol & Rat cardiac Muscle & Chronic alcohol consumption & $\begin{array}{l}\text { ICAT, nLC, MALDI- } \\
\text { TOF/TOF-MS }\end{array}$ & Fogle et al., 2010 \\
\hline Platycodi Radix extract & Rat liver & Alcoholic liver disease & 2-DE, MALDI-TOF-MS & An et al., 2009 \\
\hline Zinc & Piglet intestine & Intestinal function & 2-DE, MALDI-TOF-MS & $\begin{array}{l}\text { Wang et al., } \\
2009 \mathrm{~b}\end{array}$ \\
\hline Poly unsaturated fatty acids & Neonatal rat liver & $\begin{array}{l}\text { Hepatic metabolic pathways } \\
\text { study }\end{array}$ & 2-DE, MALDI-TOF/TOF-MS & Novak et al., 2009 \\
\hline Selenomethylselenocysteine & Rat plasma & $\begin{array}{c}\text { Chemoprotectice selenium intake } \\
\text { biomarkers }\end{array}$ & 2-DE, MALDI-TOF-MS & $\begin{array}{l}\text { Mahn, Toledo \& } \\
\text { Ruz, } 2009\end{array}$ \\
\hline
\end{tabular}

